\title{
On direct passive microwave remote sensing of sea spray aerosol production
}

\author{
I. B. Savelyev, M. D. Anguelova, G. M. Frick, D. J. Dowgiallo, P. A. Hwang, P. F. Caffrey, and J. P. Bobak \\ Remote Sensing Division, Code 7200, US Naval Research Laboratory, 4555 Overlook Ave, SW., \\ Washington, DC 20375, USA
}

Correspondence to: I. B. Savelyev (ivan.savelyev@nrl.navy.mil)

Received: 24 January 2014 - Published in Atmos. Chem. Phys. Discuss.: 12 June 2014

Revised: 23 August 2014 - Accepted: 25 September 2014 - Published: 5 November 2014

\begin{abstract}
This study addresses and attempts to mitigate persistent uncertainty and scatter among existing approaches for determining the rate of sea spray aerosol production by breaking waves in the open ocean. The new approach proposed here utilizes passive microwave emissions from the ocean surface, which are known to be sensitive to surface roughness and foam. Direct, simultaneous, and collocated measurements of the aerosol production and microwave emissions were collected aboard the FLoating Instrument Platform (FLIP) in deep water $\sim 150 \mathrm{~km}$ off the coast of California over a period of $\sim 4$ days. Vertical profiles of coarse-mode aerosol $(0.25-23.5 \mu \mathrm{m})$ concentrations were measured with a forward-scattering spectrometer and converted to surface flux using dry deposition and vertical gradient methods. Back-trajectory analysis of eastern North Pacific meteorology verified the clean marine origin of the sampled air mass over at least 5 days prior to measurements. Vertical and horizontal polarization surface brightness temperature were measured with a microwave radiometer at 10.7 GHz frequency. Data analysis revealed a strong sensitivity of the brightness temperature polarization difference to the rate of aerosol production. An existing model of microwave emission from the ocean surface was used to determine the empirical relationship and to attribute its underlying physical basis to microwave emissions from surface roughness and foam within active and passive phases of breaking waves. A possibility of and initial steps towards satellite retrievals of the sea spray aerosol production are briefly discussed in concluding remarks.
\end{abstract}

\section{Introduction}

As waves grow under the forcing of near-surface wind, some of their energy dissipates through whitecap-generating wave breaking. These whitecaps are progenitors of sea spray droplets ejected into the air when whitecap bubbles burst. Larger droplets quickly re-enter the water under the effect of gravity, while droplets small enough to be advected by the wind equilibrate with their surrounding and mix throughout the marine boundary layer (MBL) (de Leeuw et al., 2011). The focus of this paper is on measurement and parameterization of the production rate of these sea spray aerosol (SSA) particles in the open ocean. Of specific interest are coarse sea spray droplets, with radius at formation from $\sim 2$ to $\sim 40 \mu \mathrm{m}$, which transform by evaporation into aerosol particles with dry radii $r_{\text {dry }}=(0.5$ to 10$) \mu \mathrm{m}$ (Gerber, 1985 ; Andreas, 2002).

In the process of their formation, SSA transports momentum, heat (sensible and latent), and mass (gases, salts, and organics) between the ocean and the atmosphere (Blanchard, 1983; Andreas et al., 1995; Melville, 1996; Woolf, 1993). SSA particles act readily as cloud condensation nuclei (CCN) and scatter light efficiently because of their hydroscopicity and sizes. As CCN and via light scattering, SSA contributes to direct and indirect effects on the climate system (Andreae, 1995) and affects the visibility of the marine atmosphere, which is important for safe navigation of commercial and Navy vessels (Gathman et al., 1998). Being one of the dominant types of natural aerosols, especially in remote areas with clean marine air, SSA determines the baseline against which the effect of anthropogenic aerosols is assessed (Quinn et al., 1998). The involvement of SSA in a myriad of air-sea 
interaction, atmospheric, and climate processes necessitates accurate prediction of SSA concentrations and fluxes.

Laboratory and field measurements of SSA concentrations and/or fluxes have been used to parameterize the sea spray source function (SSSF) that estimates the SSA production for aerosol models, chemical transport models, and global climate models (Shettle and Fenn, 1979; Gathman et al., 1998; Caffrey et al., 2006; Textor et al., 2006). Though a review of recent efforts has identified advances such as a recognition of the large contribution of organic substances to SSA population and the extension of SSA observations to smaller sizes $\left(r_{\text {dry }}<0.05 \mu \mathrm{m}\right)$, uncertainty of a factor of 4-5 in measuring and parameterizing the production flux of SSA with $r_{\text {dry }}>0.5 \mu \mathrm{m}$ remains. This uncertainty is a major reason for the 2-orders-of-magnitude spread in current global annual SSA emission estimates (de Leeuw et al., 2011). Contributing to the uncertainty in estimates of SSA production are measurement difficulties and errors (Reid et al., 2006); use of oversimplified assumptions and approximations (discussed in more detail below); oversimplified use of forcing parameters, such as local wind speed alone (see Norris et al., 2013, and Ovadnevaite et al., 2014, for relevant discussion); and not accounting for various influences such as those of the wave field, atmospheric stability, seawater temperature and salinity, and the presence, amount, and nature of surfactants (Monahan and O'Muirchaertaigh, 1986; Anguelova and Webster, 2006; de Leeuw et al., 2011; Salisbury et al., 2013). A notable recommendation for constraining the SSA production flux is the use of field observations or consistent determination by multiple approaches (de Leeuw et al., 2011).

The present paper introduces a novel way to reduce some of these uncertainties by describing an empirical approach which relates SSA production to the brightness temperature of the ocean surface as measured by a microwave radiometer. Merits of the promoted approach are that (i) it avoids, or at least reduces, the use of unverified assumptions; and (ii) the brightness temperature is a suitable variable that fully characterizes the sea state, including surface roughness and foam, which are highly relevant to the SSA production. Data for this study were collected during the field Breaking Wave Experiment (BREWEX) conducted aboard the Floating Instrument Platform (FLIP) from 17 April to 3 May 2012. The overall goal of this experiment was to provide a variety of collocated measurements aimed at identifying specific signatures of active and residual phases of oceanic whitecaps utilizing visible, infrared, microwave, and acoustic sensing. This paper presents the first results of the BREWEX data analysis and primarily focuses on SSA and passive microwave radiation emissions from whitecaps, as well as on the physical and statistical relationship between the two.

\section{Background}

The scientific fields related to SSA production and to passive radiometry of ocean surface are both well developed and largely independent of each other. Since in this study a direct link is established between the two, it is instructive to present relevant backgrounds, including methodologies related to these subject areas in order to set the stage for a joint analysis, discussion, and interpretation of obtained results.

\subsection{Sea spray aerosol flux}

\subsubsection{Measurements of sea spray aerosol flux}

Lewis and Schwartz (2004) and de Leeuw et al. (2011) review a variety of methods for measuring and estimating production fluxes of SSA. This section briefly describes two specific methods, the dry deposition method and the vertical gradient method, which are used in this study for data analysis and interpretation.

As an input, the dry deposition method requires only sizedependent measurements of aerosol concentration, $N(r)$, at some height, and as a result it produces the total surface flux, $F(r)$, at a desired reference height. The upward flux is assumed to be equal to the downward flux; thus

$F(r)=V_{\mathrm{g}} \cdot N(r)$,

where $V_{\mathrm{g}}$ is the gravitational settling (or deposition) velocity, which can be estimated assuming "Stokesian" behavior of a falling droplet (Lewis and Schwartz, 2004):

$V_{\mathrm{g}}=\left(\frac{r}{8.5}\right)^{2}$

Equation (2) gives $V_{\mathrm{g}}$ in centimeters per second, and $r$ is in micrometers. Note that a variety of approaches exist for estimating deposition velocities, including dependencies on wind speed, such as Slinn and Slinn (1980); also see Anguelova (2002, Appendix D) for relevant discussion. To convert $F(r)$ from a measurement height, $H$, to the desired reference height of $10 \mathrm{~m}$ above the water level, aerosol concentration can be extrapolated using a logarithmic profile (Hoppel et al., 2002):

$\frac{N(H)}{N(z)}=\left(\frac{H}{z}\right)^{-\frac{V_{\mathrm{g}}}{\kappa u_{*}}}$,

where $\kappa$ is the von Karman constant and $u_{*}$ is the wind friction velocity.

Well-known uncertainties and applicability limitations associated with the dry deposition method arise primarily from the assumption of equilibrium between upward and downward aerosol fluxes. This assumption essentially requires that a certain surface flux existed for a sufficiently long time to saturate the MBL with droplets of a specific size. Hoppel et al. (2002) showed that, while this is less of an issue for 
larger droplets, the saturation of MBL with smaller droplets ( $r_{\text {dry }} \sim<2 \mu \mathrm{m}$ ) can take from hours to days. Over such a period, the environmental conditions giving rise to the surface flux inevitably change, making it impossible to tie measured fluxes to a specific state of the air-sea interface. Additionally, due to wet deposition (i.e., occasional rain events), the MBL is typically less than saturated with aerosols; therefore the dry deposition method is also believed to consistently underestimate the surface flux, particularly for smaller droplets.

Another method used here is the vertical gradient method (Petelski, 2003; Petelski and Piskozub, 2006). The basic assumption of this method is that droplet concentrations are perfect passive tracers and are transported through the boundary layer in the same way as other passive scalars (e.g., temperature or humidity). This allows the application of a widely used boundary layer similarity theory (Monin and Obukhov, 1954), which models the vertical profile by a logarithmic form:

$N(r, z)=N_{*}(r) \cdot \ln (z)+C(r)$,

where $N_{*}$ is defined as $N_{*}=F / u_{*}$, and $C$ is a constant independent of $z$. Vertical profiles of aerosol concentrations, $N(r, z)$, are measured in situ and used to determine $N_{*}(r)$ and $C(r)$ by fitting the best-matching logarithmic profile within each radius bin. Then, from the similarity theory, the surface flux is calculated as

$F(r)=N_{*}(r) C_{10}^{1 / 2} \cdot U_{10}$,

where $C_{10}$ is the drag coefficient of the ocean surface and $U_{10}$ is the wind speed at $10 \mathrm{~m}$ height above the water level.

The main practical difficulty associated with the vertical gradient method is that the required near-instantaneous measurements of vertical profiles $N(r, z)$ often lack statistical confidence to constrain the shape of the fitted logarithmic profiles. Therefore, it is expected to be more effective in experimental setups with multiple particle counters placed as a vertical array.

In regard to both methods, field measurements of SSA concentrations and fluxes are complicated by the presence of different types of aerosols other than whitecap-produced SSA. The SSA generated locally are usually mixed up with air masses coming from different sites and bringing either aged SSA from other remote marine areas or particles from continental sources with natural or anthropogenic origins. Modeling trajectories of air masses back in time to determine their origin and transport is a tool that allows assessment of the predominance of SSA or other aerosols at the time and site of observation. For example, the purity and usability of collected SSA data were assessed in Caffrey et al. (2006) by calculating wind back trajectories using an output of a meteorological circulation model.

\subsubsection{Parameterizations of sea spray aerosol flux}

Although many methods and resulting parameterizations exist in the literature (Lewis and Schwartz, 2004), most authors use or compare to parameterizations by Monahan et al. (1986) and Smith et al. (1993). This makes them a convenient frame of reference for the results presented in this paper.

The sea spray source function, defined here as the surface flux function $\mathrm{d} F / \mathrm{d} r$ or $\mathrm{d} F / d(\ln r)$, is used to parameterize the number of SSA particles with radii in a given infinitesimal range propagating upwards per unit area per unit time. This derivative is considered to be the final and most general output of various measuring methods that can be used as a source term by atmospheric aerosol models (e.g., Caffrey et al., 2006). A common practice is to assume a separation of variables, such as $\mathrm{d} F\left(r, U_{10}\right) / \mathrm{d}(\ln r)=f(r) \cdot g\left(U_{10}\right)$, where $f(r)$ is a universal shape function depending solely on the droplet radius, and $g\left(U_{10}\right)$ is a dimensionless scaling function that contains dependence on relevant environmental forcing factors, which are often simplified to a function of only the wind speed $U_{10}$.

To obtain the surface flux, $F$, Smith et al. (1993) conducted long-term size-resolved field measurements of SSA concentrations, which were converted to an SSSF parameterization using the dry deposition method (see Sect. 2.1.1). The parameterization by Monahan et al. (1986) uses the whitecap method, which combines a separately obtained function, $f(r)$, and a scaling whitecap fraction, $W$. The scaling factor, $W$, is necessary for open-ocean conditions because $f(r)$ is obtained from laboratory (Monahan et al., 1982) or surf zone (de Leeuw et al., 2000) measurements of surface flux per unit area of whitecap. Monahan et al. (1986) formulated $f(r)$ in terms of radius and whitecap fraction, $W$, in terms of wind speed: $\mathrm{d} F / \mathrm{d} r=W\left(U_{10}\right) \cdot f(r)$. Unlike the dry deposition and the vertical gradient methods, the whitecap method was not used to obtain SSSF in the analysis presented here; however, some basic concepts and assumptions behind the method are relevant to this study. The validity of assumptions used in various SSSF parameterizations is further discussed in Sect. 6.2.

\subsubsection{Input variables for sea spray aerosol flux parameterizations}

The most important and common parameter used to constrain the SSA production flux is wind speed at $10 \mathrm{~m}$ reference height, $U_{10}$, because wind is the main forcing factor that leads to growth of waves, which ultimately break and produce foam and consequently aerosol. In addition to the localized wind speed, $U_{10}$, breaking-wave activity at a particular location is also a function of the wave field which is formed in response to large-scale spatial and temporal distributions of wind. Therefore, the common practice of approximating relevant forcing with local $U_{10}$ alone is a significant 
simplification. This practice could, at least partially, explain the wide data scatter observed within SSSF studies, as well as large differences among existing SSSF parameterizations.

To account for the relevant history of winds and waves, additional factors such as duration and fetch of the wind, as well as the atmospheric stability, can be considered (Kara et al., 2008). The existing state of the wave field can be characterized directly by significant wave height, peak wave period, wave slope, or wave age. A more complete SSSF parameterization should include some of these factors. Developing an SSSF parameterization in terms of wind stress or wind friction velocity allows atmospheric stability to be incorporated during the conversion of locally measured $U_{10}$, if temperature and humidity profiles are also available. For the whitecap method, additional influences can be included through the parameterization of the whitecap fraction used as a scaling factor in SSSF. Motivated by such reasoning, Lafon et al. (2004) parameterized $W$ in terms of wind fetch. Zhao and Toba (2001) accounted for wave properties with a wavebreaking parameter, which in turn depends on wind speed and peak wave frequency. Fairall et al. (2009) conducted a laboratory investigation of spume drop production as a function of breaking-wave probability. Most recently, Norris et al. (2013) and Ovadnevaite et al. (2014) parameterized SSSF directly in terms of Reynolds number, defined by wind friction velocity and significant wave height.

Environmental factors like sea surface temperature, salinity, and the presence and amount of surface active materials also affect the production of sea spray through a variety of processes. Foremost, they influence the extent and persistence of the whitecaps where bubble bursting produces sea spray droplets.

\subsection{Brightness temperature of the ocean surface}

The large number of relevant environmental parameters influencing the SSA production and the complexity of their interactions motivated the search for a source of measurements of the ocean surface capable of capturing most, if not all, of the relevant processes. This study suggests that one possibility is the brightness temperature of the ocean surface, which can be measured by microwave radiometers on ships, aircrafts, and satellites. A brief background introducing this parameter is given below.

\subsubsection{Brightness temperature definition}

Any matter at a physical temperature above absolute zero emits thermal energy in the form of electromagnetic (EM) waves. The intensity of the radiated energy is directly related to the physical temperature, $T$, of the object. It is also related to the physical properties of the material through the emissivity, $e$. The intensity is termed the brightness temperature, $T_{\mathrm{B}}: T_{\mathrm{B}}=e(f, P, \theta) T$, where emissivity is a function of frequency, $f$; polarization, $P(P=H$ for horizontal and $V$ for vertical polarizations); and incidence angle, $\theta$. The relationship between measured brightness temperature and the physical properties, as expressed through the emissivity, can be of more interest than the specific physical temperature. That is the case in the present work. For more general background on brightness temperature see Ulaby et al. (1981).

\subsubsection{Measurements of sea surface brightness temperature}

The measured brightness temperature when viewing the ocean surface is

$$
\begin{aligned}
& T_{\mathrm{B}}(f, P, \theta)=T_{\text {up }}(f, \theta, h)+\alpha(f, \theta, h)\left\{(1-r(f, P, \theta)) T_{\mathrm{s}}\right. \\
& \left.+r(f, P, \theta) T_{\text {down }}(f, \theta)\right\},
\end{aligned}
$$

where $T_{\text {up }}$ is the upwelling brightness temperature of the atmosphere between the surface and the sensor, $\alpha$ is the transmissivity of the atmosphere between the surface and sensor, $r$ is the reflectivity of the sea surface, $T_{\mathrm{S}}$ is the surface temperature of the ocean, $T_{\text {down }}$ is the downwelling brightness temperature of the atmospheric column (and cosmic background), and $h$ is the height of the observation.

For the observations from FLIP, $h$ is small enough, especially at the observation frequency of $10.7 \mathrm{GHz}$ (where the atmosphere has low attenuation), so that $T_{\text {up }}$ is negligible, as are atmospheric losses between the ocean and the sensor; therefore $\alpha \approx 1$. Further, the ocean can be assumed to be semi-infinite, with no transmission, so $1=r+e$. The brightness temperature can then be approximated as

$T_{\mathrm{B}}(f, P, \theta)=e(f, P, \theta) T_{\mathrm{s}}+(1-e(f, P, \theta)) T_{\text {down }}(f, \theta)$.

At $10.7 \mathrm{GHz}, T_{\text {down }}$ is relatively small, particularly in cloudfree conditions, in which it is on the order of $10 \mathrm{~K}$, and the first term dominates the measured brightness temperature.

The emissivity, in addition to the dependencies explicit in the equation, is a function of the roughness of the sea surface and the amount of sea foam present. The average emissivity of a scene can be represented as the sum of lower emissivity rough surface (with emissivity, $e_{\mathrm{r}}$ ) and higher emissivity foam patches (with emissivity, $e_{\mathrm{f}}$ ), weighted by the fractional areal coverage of whitecaps, $W$ :

$e=(1-W) e_{\mathrm{r}}+W e_{\mathrm{f}}$.

The high emissivity of sea foam increases the emissivity of the ocean (Anguelova and Gaiser, 2012) when $W>0$.

\subsubsection{Satellite-based observations of brightness temperature}

Satellite-based observations of the ocean provide long-term data coverage on a global scale and are of obvious interest and importance. Brightness temperature measurements from satellites, as opposed to the measurements from FLIP, include the full impact of the atmosphere between the sensor 
and sea surface. That is, the radiative processes of absorption, scattering, and emission occurring within the atmosphere both attenuate the signature arising from the sea surface and add intensity consistent with the atmospheric parameters. To account for these additional processes, and thus correctly describe the brightness temperature at the top of the atmosphere (TOA), one needs to use a radiative transfer model.

Having TOA observations introduces both useful and complicating aspects to the processing of radiometric $T_{\mathrm{BP}}$ data: useful because $T_{\mathrm{BP}}$ data now also carry information about atmospheric variables, such as columnar water vapor, cloud liquid water, and precipitation, which can be retrieved from satellite observations (Wentz, 1997); complicating because to retrieve near-surface variables, the atmospheric component has to be removed by means of an atmospheric correction. The quality of the atmospheric model that evaluates and removes the atmospheric component, and the accuracy of the atmospheric parameters (temperature, water vapor, etc.) needed to evaluate it, can significantly impact the accuracy of the retrievals at the ocean surface, particularly at higher frequencies with higher atmospheric absorption or in the presence of clouds and precipitation. Currently, global radiometric measurements for atmospheric and surface geophysical variables are available from several sensors, including WindSat, the Special Sensor Microwave Imager/Sounder (SSMIS), the Advanced Microwave Scanning Radiometer-2 (AMSR-2), and the Global Precipitation Measurement Microwave Imager (GMI).

\subsubsection{Modeling the brightness temperature}

In this study, we use the model developed by Hwang (2012, hereafter H12), which is capable of evaluating the total signal, $T_{\mathrm{BP}}$, as well as all of its components separately. A brief summary of H12 is given below; Hwang (2012) provides a detailed description.

H12 models the ocean surface emissivity and thus its brightness temperature as the sum of the baseline radiation of a flat water surface, an increase in emissivity due to surface roughness, and an additional term representing the contribution of sea foam generated by breaking waves. The baseline contribution is the emissivity of a flat seawater surface, $e_{0}$, at a given temperature, $T_{\mathrm{s}}$, and salinity, $S$, usually measured as a specular reflection, $r_{0}$. As long as $T_{\mathrm{S}}$ and $S$ remain constant, $r_{0}$ and thus $e_{0}=1-r_{0}$ do not change. Scattering from roughness elements caused by long waves (e.g., swell and long gravity waves) and short waves (e.g., short gravity and capillary waves) increases the specular reflection to $r=r_{0}+\delta r$. As the sea surface roughness increases with the wind speed, $U_{10}$, so does the surface scattering contribution, $\delta r$, and the overall reflectivity of rough sea surface, $r$. From Kirchoff's law, the emissivity of rough surface changes to $e_{\mathrm{r}}=1-r=1-r_{0}-\delta r=e_{0}-\delta r$, which gives

$e=(1-W) e_{\mathrm{r}}+W e_{\mathrm{f}}=(1-W) e_{0}-(1-W) \delta r+W e_{\mathrm{f}}$.
Polarized ocean surface emissivity (Eq. 6) is indirectly measured by radiometers as polarized brightness temperature, $T_{\mathrm{BP}}$ :

$$
T_{\mathrm{BP}}=e_{\mathrm{P}} T_{\mathrm{S}}=T_{\mathrm{S}}\left[(1-W) e_{0 \mathrm{P}}-(1-W) \delta r_{\mathrm{P}}+W e_{f \mathrm{P}}\right]
$$$$
=T_{\mathrm{B} O \mathrm{P}}+T_{\mathrm{BrP}}+T_{\mathrm{BfP}} \text {. }
$$

Equation (7) demonstrates that $T_{\mathrm{BP}}$ at the surface carries information about the main features of the ocean surface, such as its temperature and salinity in term $T_{\mathrm{B} 0 \mathrm{P}}$, sea surface roughness in term $T_{\mathrm{BrP}}$, and sea foam in term $T_{\mathrm{BfP}}$. Radiometric $T_{\mathrm{BP}}$ data are thus used to infer (retrieve) various geophysical parameters such as near-surface wind speed and direction, sea surface temperature, salinity, and whitecap fraction (Wentz, 1997; Koblinsky et al., 2003; Bettenhausen et al., 2006; Anguelova and Webster, 2006). These, in turn, are variables which are often used as input values in other parameterizations, including SSSF parameterizations based on $U_{10}$. However, a direct parameterization of SSSF in terms of $T_{\mathrm{BP}}$ could be more desirable, because $T_{\mathrm{BP}}$ data represent a snapshot of the sea state as created by both present (e.g., local $U_{10}, T_{\mathrm{s}}$, and $S$ ) and past (e.g., fetch and duration of the wind) conditions. Therefore, observations of $T_{\mathrm{BP}}$ represent the sea state more fully than other commonly used environmental parameters.

Equation (7) represents a general road map of modeling the brightness temperature of the ocean surface. The sea surface temperature, $T_{\mathrm{s}}$, is usually available from measurements or from numerical prediction models. Whitecap fraction, $W$, can be either measured or parameterized in terms of wind speed, $U_{10}$ (Monahan and O'Muirchaertaigh, 1980). The rest of the terms - namely the specular (flat surface) emissivity, $e_{0 \mathrm{P}}$; the correction for the scattering of rough surface, $\delta_{\mathrm{rP}}$; and the foam emissivity, $e_{\mathrm{fP}}-$ can be modeled (Stogryn, 1972; Pandey and Kakar, 1982; Yueh, 1997; Johnson, 2006).

The approach in $\mathrm{H} 12$ is to express the brightness temperature $T_{\mathrm{B}}$ at $H$ and $V$ polarizations and microwave frequency $f$, incidence angle $\theta$, and azimuth angle (with respect to the wind direction) $\varphi$, with two major terms, one for the emissivity of a flat surface and another for wind-induced emissivity change (Johnson and Zhang, 1999; Reul and Chapron, 2001):

$T_{\mathrm{BP}}(f, \theta, \varphi)=T_{\mathrm{S}}\left[\left(1-\left|R_{\mathrm{PP}}^{(0)}\right|^{2}\right)+\delta e_{\mathrm{P}}\right]$,

where $R_{\mathrm{PP}}^{(0)}(f, \theta)$ is the Fresnel reflection coefficient of polarization, $P$. The wind-induced term $\delta e_{\mathrm{P}}(f, \theta, \varphi)$ includes contributions from rough and foamy sea surfaces; thus Eq. (8) can be written as

$$
\begin{aligned}
& {\left[\begin{array}{l}
T_{\mathrm{BH}}(f, \theta, \varphi) \\
T_{\mathrm{BV}}(f, \theta, \varphi)
\end{array}\right]=T_{\mathrm{S}}\left\{\left[\begin{array}{c}
e_{0 \mathrm{H}} \\
e_{0 \mathrm{~V}}
\end{array}\right]+\left[\begin{array}{c}
\delta e_{\mathrm{rH}} \\
\delta e_{\mathrm{rV}}
\end{array}\right]+\left[\begin{array}{c}
\delta e_{\mathrm{fH}} \\
\delta e_{\mathrm{fV}}
\end{array}\right]\right\}} \\
& =\left[\begin{array}{c}
T_{\mathrm{B} 0 \mathrm{H}} \\
T_{\mathrm{B} 0 \mathrm{~V}}
\end{array}\right]+\left[\begin{array}{l}
\delta T_{\mathrm{BrH}} \\
\delta T_{\mathrm{BrV}}
\end{array}\right]+\left[\begin{array}{l}
\delta T_{\mathrm{BfH}} \\
\delta T_{\mathrm{BfV}}
\end{array}\right] .
\end{aligned}
$$


In Eq. (9), the specular emissivity term is calculated as $e_{0 \mathrm{P}}=$ $1-r_{0 \mathrm{P}}$, where $r_{0 \mathrm{P}}$ is obtained with the Fresnel formula. The dielectric constant of seawater, necessary for evaluation of the Fresnel formula, is that of Meissner and Wentz (2004). Well-established methods for computing the scattering from rough sea surface, $r_{\mathrm{P}}$, are the two-scale model (Wentz, 1975; Yueh, 1997; Johnson, 2006; Lyzenga, 2006) and smallperturbation method/small-slope approximation (SPM/SSA) (Yueh et al., 1994a, b; Johnson and Zhang, 1999). The H12 model uses the original SPM/SSA code of Reul and Chapron (2001) to obtain $r_{P}$ and then calculates the change in emissivity due to roughness as $\delta e_{\mathrm{rP}}=e_{\mathrm{rP}}-e_{\mathrm{OP}}=\left|\delta r_{\mathrm{P}}\right|$. The change in emissivity due to foam is $\delta e_{\mathrm{fP}}=1-\delta r_{\mathrm{fP}}$, where $\delta r_{\mathrm{fP}}$ is obtained from the Fresnel formula and the quadratic mixing rule for the dielectric constant of sea foam (Anguelova, 2008) as described in Hwang (2012). Within this approach, $\delta e_{\mathrm{fP}}$ incorporates the weighting factor, $W$ (as in Eq. 7), implicitly; see Appendix for more details. The capability of H12 to separately model the contributions of different sea states to the total $T_{\mathrm{BP}}$ is exploited further in this paper for analysis (Sect. 5) and interpretation (Sect. 6.1) of field data.

\section{Experiment}

Measurements presented here were collected as part of the BREWEX field experiment conducted from 17 April to 3 May 2012, i.e., year days (YDs) 108-124. Details of the experiment will be published separately; here we present a subset of collected measurements that are relevant to the specific goals of this paper.

\subsection{Experimental site}

FLIP is a unique vessel (http://www-mpl.ucsd.edu/ resources/flip.intro.html) that provides a stable open-ocean research platform for near-surface measurements. FLIP was towed in a horizontal orientation from San Diego north towards a location $\sim 150 \mathrm{~km}$ west from Monterey Bay. At that location on 21 April (YD 112), FLIP was flipped into vertical orientation through ballast changes and was allowed to move with ocean currents for the next 9 days. The platform moved generally south, along the coast of California over water depth of $\sim 3000 \mathrm{~m}$. The experiment site thus provided deep water breaking conditions, which are suitable for comparisons of the data to satellite observations in open ocean. The season and location were chosen to provide relatively high winds and limited precipitation.

\subsection{Instrumentation}

When vertical, FLIP becomes a $\sim 109 \mathrm{~m}$ high spar buoy with a draft of $\sim 85 \mathrm{~m}$. The diameter of the hull tapers close to the sea surface, thus minimizing FLIP's response to wave motion. Three $\sim 18 \mathrm{~m}$ long horizontal booms are deployed on the port, starboard, and face sides of FLIP. Instruments are mounted on or under the booms as far from hull as possible so that measured currents and winds are undisturbed by FLIP's hull. In drift mode (as opposed to moored mode), FLIP rotates with the wind so the bottom (convex side) of the hull is always oriented upwind. In this way, instrumentation mounted on port and starboard booms remains exposed to an unperturbed airflow, while the face boom is always sheltered by the hull.

A forward-scattering spectrometer, CSASP-100-HV of Particle Measuring Systems (PMS), measured sea spray aerosol size distribution for particle radii, $r$, from 0.25 to $23.5 \mu \mathrm{m}$ (coarse mode). While scattering spectrometers of this type are known to have accuracy limitations (Reid et al., 2006), this particular instrument has been tested and proven reliable in numerous experiments (Hoppel et al., 1994; Frick and Hoppel, 2000). The PMS instrument was suspended from the starboard boom at $\sim 7.3 \mathrm{~m}$ height above the mean water level (MWL) and approximately $7 \mathrm{~m}$ away from the FLIP hull. The suspension height was controlled by a motorized winch, which allowed occasional measurements of vertical profiles at lower heights down to $4.9 \mathrm{~m}$.

Ocean surface brightness temperatures, $T_{\mathrm{B}}$, were measured at frequencies of 10.7 and $37 \mathrm{GHz}$ and vertical and horizontal $(V$ and $H$ ) polarizations using a subset of the Airborne Polarimetric Microwave Imaging Radiometer (APMIR) (Bobak et al., 2001, 2011). The radiometers were mounted on the port boom $(\sim 13 \mathrm{~m}$ above MWL) in an environmental enclosure with a low-loss dielectric cover (Cuming Microwave PF3) providing a window for viewing the scene. Data were taken downwind at an incidence angle of $45^{\circ}$, giving an elliptical footprint of approximately $1.4 \mathrm{~m} \times 2.7 \mathrm{~m}$. The incidence angle was chosen from geometric considerations, allowing the radiometers to view an area of sea surface that was monitored by other in situ instrumentation used in BREWEX. Incidence angle and polarization rotation caused by variations in pointing angle from platform or boom motion were monitored with an inclinometer system mounted in the radiometer enclosure.

The radiometers are a total power design, which provides maximum sensitivity. End-to-end calibration of the radiometers was provided by rotating the enclosure to left and right to look at two external targets mounted on the port boom. The cold target was a metal sheet reflecting sky radiation, and the warm target was microwave-absorbing material at ambient air temperature. Both targets were protected with low-loss dielectric covers. Internal calibration allowed correcting for the radiometer's thermal gain drift during intervals between the external, end-to-end calibrations. The internal calibration was provided by noise diodes and ambient terminations.

A meteorological station (Vaisala WXT520 Weather Transmitter) was mounted on the end of the starboard boom $10 \mathrm{~m}$ above the MWL to measure six weather parameters: wind speed, wind direction, air temperature, relative humidity $(\mathrm{RH})$, barometric pressure, and rainfall. The same suite of data was measured with a second meteorological station 

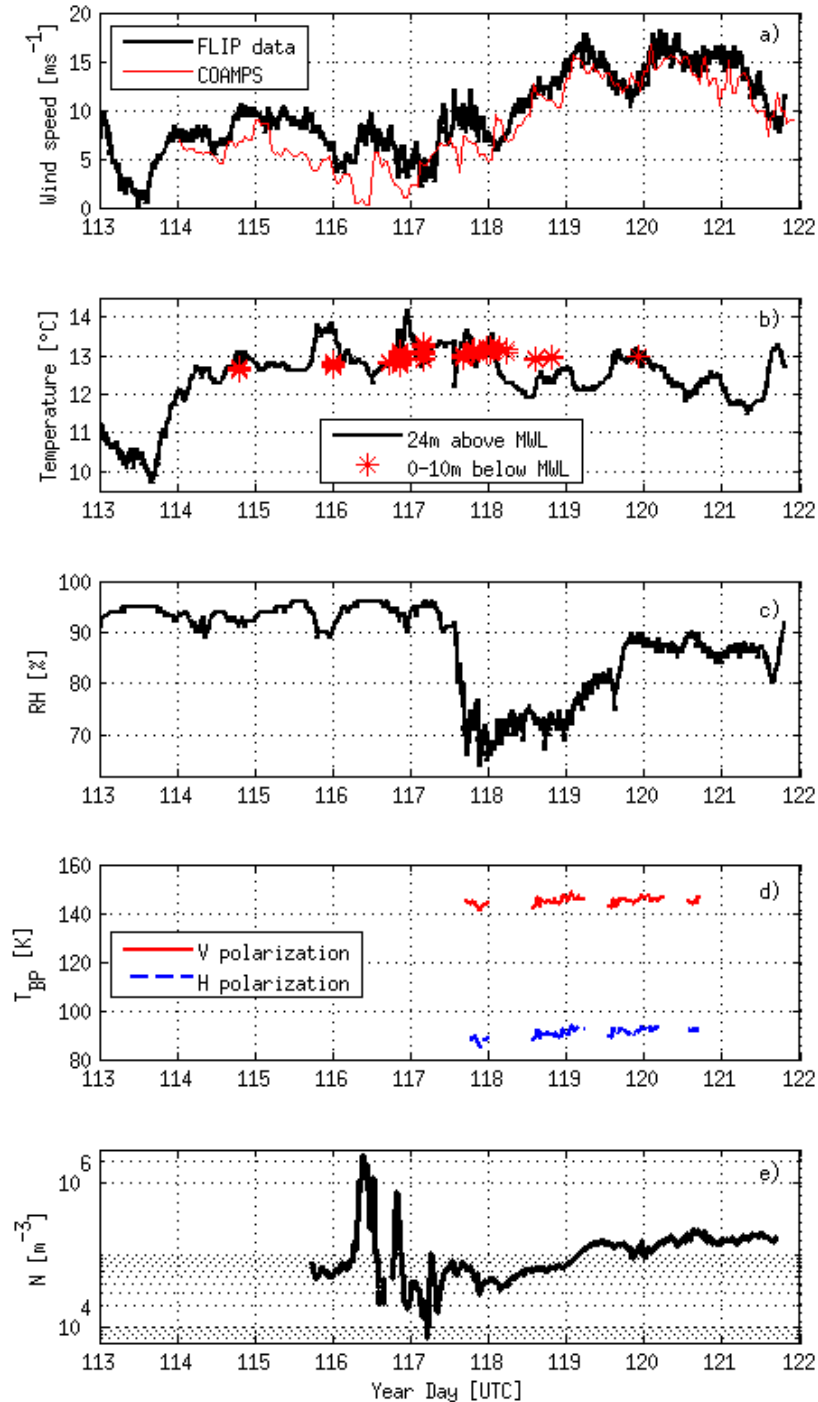

Figure 1. Overview of time series collected during the experiment, including wind speed (measured and modeled by COAMPS) (a); air and water temperatures (b); relative humidity (c); $10.7 \mathrm{GHz}$ microwave brightness temperatures (vertical and horizontal polarizations) (d); and aerosol concentration in the air (e).

(Davis 6152C Cabled Vantage Pro2) mounted in the FLIP basket $24 \mathrm{~m}$ above the MWL. Sub-surface temperature profiles within the top $10 \mathrm{~m}$ of the water column were occasionally measured with a hand-held conductivity-temperaturepressure profiler.

\section{Observations}

Figure 1 shows an overview of time series of all measured data relevant to this study. Times of measurements are given here in coordinated universal time (UTC, -7 from the local time) as a decimal of the YD. The following sections give details about the measurements shown in Fig. 1, starting with

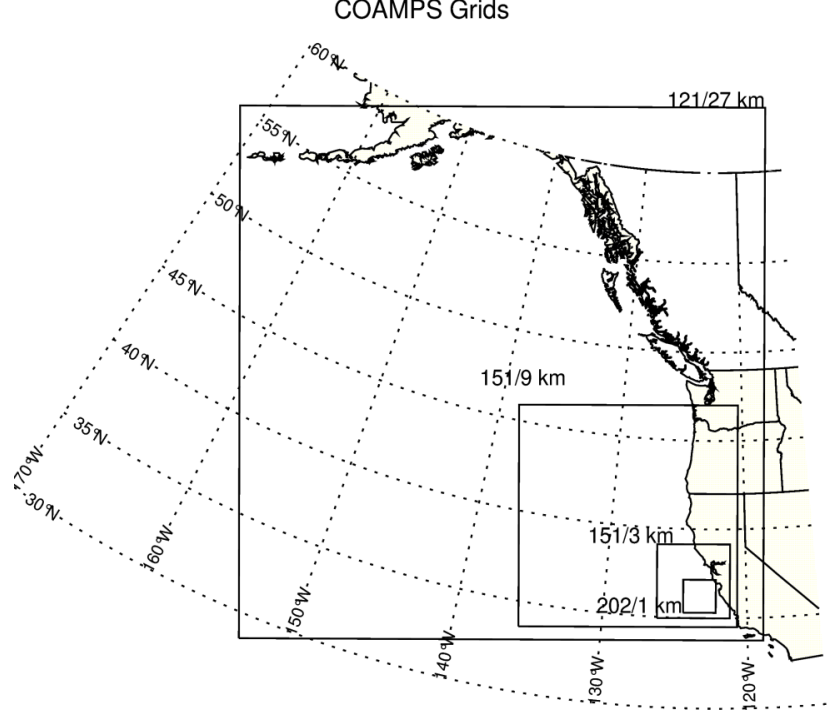

Figure 2. Locations of COAMPS computational grids in the eastern North Pacific. Number of grid points and spacing between them are given for each grid.

a discussion of the data collection, quality control, and processing procedures followed by a description of the data collected and the experimental conditions.

\subsection{Meteorological data}

Collection of meteorological data started on YD 113. The Vaisala weather station collected data at sampling rate of $5 \mathrm{~s}$, while the Davis weather station recorded one data point every 10 min. Records from the Vaisala and Davis weather stations were in excellent agreement. The Davis station provided the longest record, and it is used to illustrate the overall meteorological conditions during BREWEX (Fig. 1a-c). The output of the Vaisala station is, however, used in the analysis because it provides more precise measurements and because it was located at $10 \mathrm{~m}$ above the MWL, eliminating the need for vertical extrapolation to a reference height.

Large-scale background meteorological conditions during BREWEX were obtained from the U.S. Navy Coupled Ocean-Atmosphere Mesoscale Prediction System (COAMPS), version 4.2.2. COAMPS uses four nested grids with horizontal spatial resolutions of $27,9,3$, and $1 \mathrm{~km}$, each containing 65 vertical levels (Fig. 2). Predictive algorithms determine the most realistic atmospheric conditions over the area of interest, with the nested grids located so as to capture the upwind conditions. COAMPS reanalysis is initialized by assimilating archived historical observations of the boundary conditions available from the U.S. Navy Operational Global Atmospheric Prediction System (NOGAPS). The reanalysis runs conducted for BREWEX used $12 \mathrm{~h}$ data assimilation cycles from 24 to 30 April 2012. COAMPS wind data are given at $10 \mathrm{~m}$ height reference. Time series of COAMPS data were 
constructed by sampling $U_{10}$ values on a $1 \mathrm{~km}^{2}$ grid with a $1 \mathrm{~h}$ step around the current FLIP position.

Figure 1a compares wind speeds, $U_{10}$, from the Davis weather station on FLIP to those from COAMPS. A wide range of conditions were encountered during BREWEX, with $U_{10}$ ranging from $2.8 \mathrm{~m} \mathrm{~s}^{-1}$ on YD 113 to about $18 \mathrm{~m} \mathrm{~s}^{-1}$ on YD 120. Considering the difference in the spatial resolution of the FLIP and COAMPS data, the modeled $U_{10}$ values (red line in Fig. 1a) reproduce the measured $U_{10}$ values fairly well. Figure $3 a$ and $b$ show snapshots of COAMPS simulations of the large-scale pattern of near-surface winds on YD 118 at 20:00 UTC overlaid on the drift track of FLIP. Evident in Fig. 3a is a large synoptic system that influenced the area on this day. A close look at the experimental site on YD 118 (Fig. 3b) shows strong wind speed $\left(>12 \mathrm{~m} \mathrm{~s}^{-1}\right.$ ) almost aligned with the coast line, as expected from the April climatology for this area (Wyllie, 1966; Chelton, 1984).

The air temperature (Fig. 1b) changed most noticeably on YD 113 , from less than 10 to above $12^{\circ} \mathrm{C}$. In the period of radiometric data collection the air temperature remained relatively stable with diurnal variations also within $2^{\circ} \mathrm{C}$, between 12 and $\sim 14^{\circ} \mathrm{C}$. The seawater temperature in the mixed layer (0-10 m below MWL) was nearly constant and uniform at $\sim 13^{\circ} \mathrm{C}$ (red symbols in Fig. 1b). The air-seawater temperature difference was within $\pm 1{ }^{\circ} \mathrm{C}$, primarily caused by diurnal variations. Relative humidity (Fig. 1c) was above $90 \%$ initially, then dropped to around $70 \%$ on YD 117. From YD 119 to 121 , RH increased gradually back to $\sim 90 \%$. In combination, these observations suggest the existence of wellmixed boundary layers above and below the air-sea interface with weak vertical heat flux; thus the atmospheric stability conditions can be characterized as near-neutral.

COAMPS data were also used to run the HySplit (Hybrid Single-Particle Lagrangian Integrated Trajectory) program to generate back trajectories of wind passing through the FLIP location. Wind speed values were obtained from the COAMPS reanalysis output at $1 \mathrm{~h}$ intervals along the back trajectories out to $120 \mathrm{~h}$ earlier from the corresponding moment of data collection on FLIP. Back trajectories were calculated using the three-dimensional velocity field from the reanalysis data from COAMPS, but with the vertical motion restricted to levels of constant potential temperatures (isentropic surfaces).

Figure 4 shows back trajectories of air masses passing though the FLIP location daily at 20:00 UTC. The beginning of each trajectory is shown with the YD of arrival at the FLIP location. Wind speed history corresponding to each back trajectory is shown on the lower panel. These back trajectories show that the air mass at FLIP between YDs 117 and 121 is clean marine air that has been propagating above the North Pacific for at least 5 days. This verifies that for the given time frame the aerosol composition was predominantly of marine origin, and that the marine boundary layer had sufficient time to get saturated with the sea spray aerosols. The back trajectory of YD 116 comes from the opposite direction, thus likely (a)

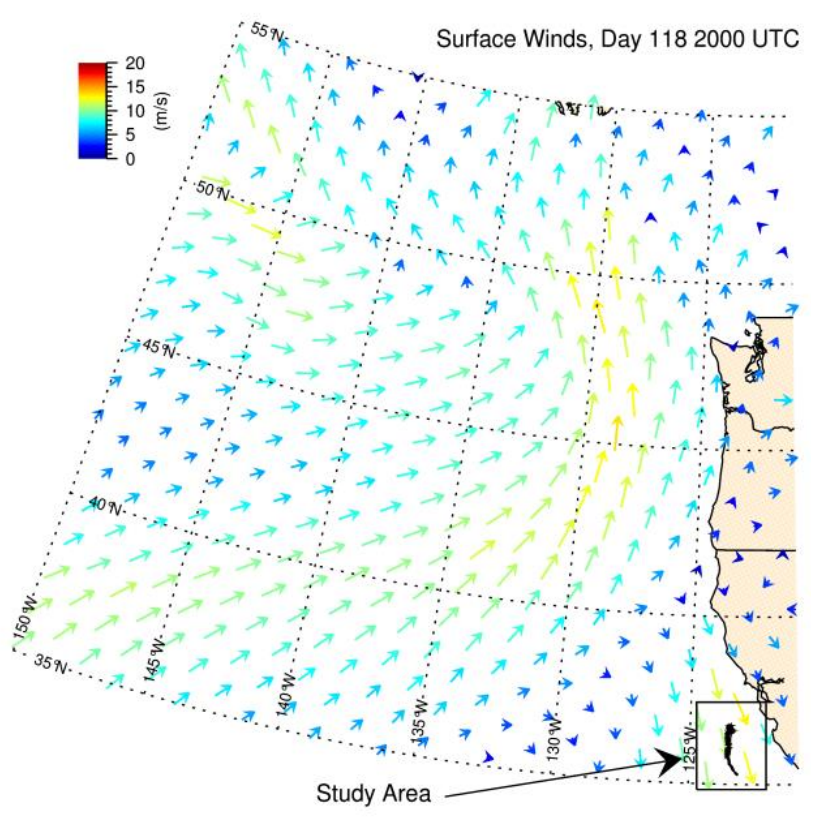

(b)

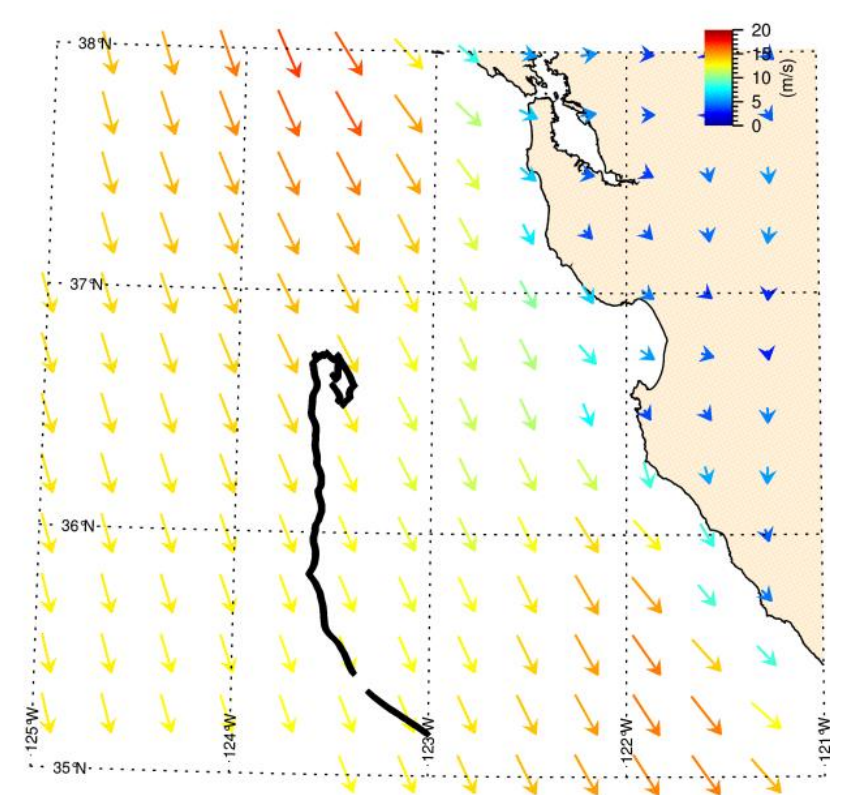

Figure 3. Snapshot of surface winds output from COAMPS on year day 118 at 20:00 UTC. Two panels represent a wider view of the eastern North Pacific and a zoomed-in view around the FLIP track, shown with the black line. 


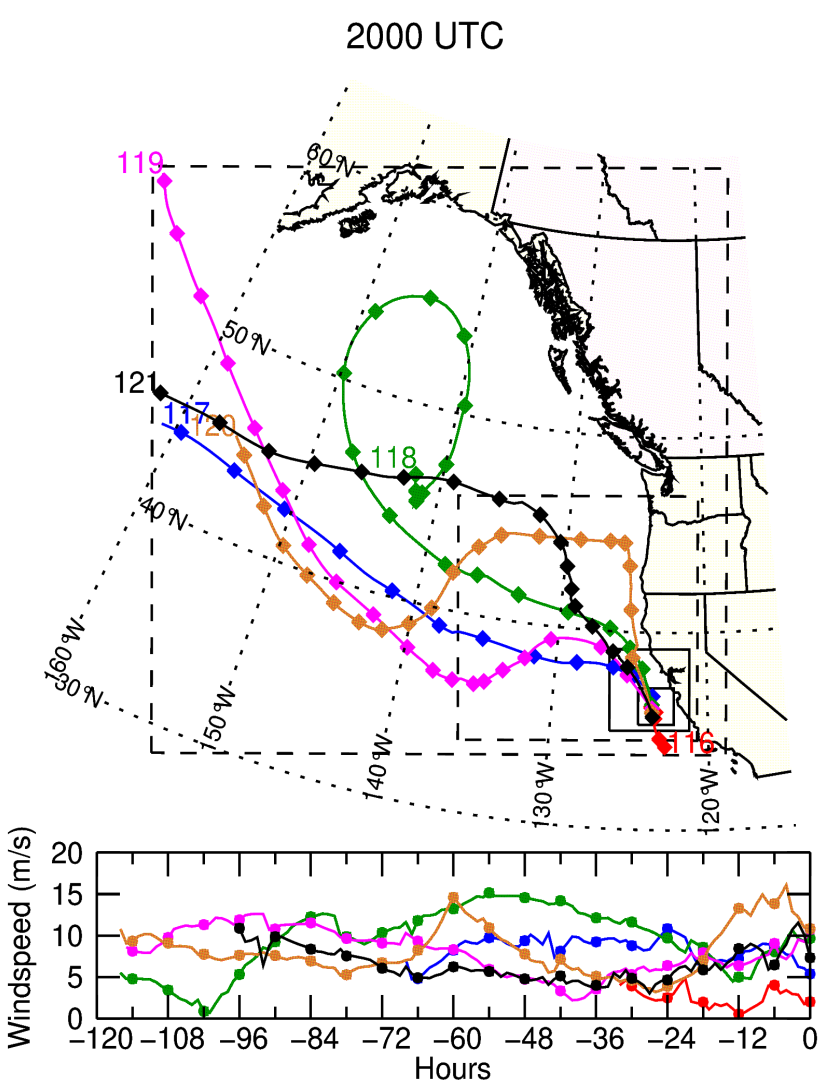

Figure 4. Back trajectories of air masses passing though FLIP location daily at 20:00 UTC. Year day of the passing is shown by a number in the beginning of each trajectory. Wind speed history corresponding to each back trajectory is shown on the lower panel.

advecting continental air masses. The full trajectory is not shown in Fig. 4 because it quickly exits the analysis domain.

\subsection{Brightness temperature data}

Brightness temperatures, $T_{\mathrm{B}}$, from the $10.7 \mathrm{GHz}$ radiometer are used in this study; data from the $37 \mathrm{GHz}$ radiometer were found unusable due to a bias, which was not able to be replicated, most likely caused by an obstruction in its field of view.

Radiometric data were stored over discrete intervals of approximately $20 \mathrm{~min}$ during YDs 117-120. Fewer data were stored under conditions of low winds (e.g., two $20 \mathrm{~min}$ intervals per day), and more in high wind conditions with 5 to $2320 \mathrm{~min}$ intervals per day. Total of $6020 \mathrm{~min}$ intervals (i.e., $20 \mathrm{~h}$ ) of data were recorded.

During each $20 \mathrm{~min}$ interval, the data were collected continuously at a sampling rate of $20 \mathrm{~Hz}$. Due to the high variability of instantaneous brightness temperature, and in order to match the moving average windows applied to other time series (Sect. 4.3), all $T_{\mathrm{B}}$ samples within one $20 \mathrm{~min}$ interval were averaged to provide a single data point. Linear inter- polation between the 20 min averaged values was used when necessary.

The resulting time series of brightness temperature at horizontal and vertical polarizations, $T_{\mathrm{BH}}$ and $T_{\mathrm{BV}}$, are shown in Fig. 1d. Both polarizations show a steady increase with increasing wind speed (Fig. 1d and a) over a range of $\sim 10 \mathrm{~K}$ for $T_{\mathrm{BH}}$ (dashed blue line) and a range of $\sim 5 \mathrm{~K}$ for $T_{\mathrm{BV}}$ (red solid line). The $10.7 \mathrm{GHz}$ brightness temperature variations are dominated by variation in the emissivity of the sea surface within the antenna footprint; the reflected downwelling brightness temperature arising from the atmosphere and cosmic background is a secondary factor. Figure 4 shows that these radiometric data were collected during days when clean marine air masses were passing FLIP.

Various polarization differences, polarization ratios, and variances were calculated and tested, and the key relationship in this study was found to rely on the difference in behavior between the vertically and horizontally polarized brightness temperatures. More specifically, the variables we found most useful in the analysis of data acquired during BREWEX are defined as follows:

$\delta T_{\mathrm{BP}}=T_{\mathrm{BP}}-T_{\mathrm{B} 0 \mathrm{P}}=\delta T_{\mathrm{BrP}}+\delta T_{\mathrm{BfP}}$,

$\Delta T_{\mathrm{B}}=\delta T_{\mathrm{BH}}-\delta T_{\mathrm{BV}}$,

where $\delta T_{\mathrm{BP}}$ is the measured brightness temperature minus the modeled brightness temperature of a flat surface, $T_{\mathrm{B} 0 \mathrm{P}}$, in otherwise similar conditions (Eqs. 7 and 9), calculated using the Meissner and Wentz (2004) model. Input parameters used in this calculation were the radiometer frequency $f=10.7 \mathrm{GHz}$, incidence angle $\theta=45^{\circ}$, water temperature $T_{\mathrm{S}}=13^{\circ} \mathrm{C}$, and salinity $S=32.6 \%$, resulting in flat-surface brightness temperature values $T_{\mathrm{B} 0 \mathrm{H}}=81.8^{\circ} \mathrm{K}$ and $T_{\mathrm{B} 0 \mathrm{~V}}=$ $140.2^{\circ} \mathrm{K}$. The parameter $\delta T_{\mathrm{BP}}$ on the left-hand side of Eq. (9) is an attempt to minimize the dependence on these variables (i.e., $T_{\mathrm{S}}$ and $S$ ) and instead focus on the impact of surface foam and roughness, which are expected to be most relevant to the SSA production. As Eq. (9) shows, these windinduced $\delta T_{\mathrm{BP}}$ values are the measured counterparts of the wind-induced modeled values $\delta T_{\mathrm{BrP}}+\delta T_{\mathrm{BfP}}$ in Eq. (9). The parameter $\Delta T_{\mathrm{B}}$ introduced in Eq. (10) is the difference between horizontal and vertical polarization of $\delta T_{\mathrm{BP}}$ parameters. This parameter approximately removes foam contribution for low to moderate wind speeds and, thus, more accurately represents the roughness contribution alone (further discussed in Sect. 6.1).

\subsection{Sea spray aerosol data}

Aerosol data were collected from late YD 115 to 121 . The PMS particle counter measures size-resolved aerosol concentrations, $N(r)$, in the range from 0.25 to $23.5 \mu \mathrm{m}$ by alternating every $4 \mathrm{~s}$ between four sub-ranges: $\quad 1.0 \mu \mathrm{m}<r<23.5 \mu \mathrm{m}, \quad 1.0 \mu \mathrm{m}<r<16.0 \mu \mathrm{m}$, $0.5 \mu \mathrm{m}<r<8.0 \mu \mathrm{m}$, and $0.25 \mu \mathrm{m}<r<4.0 \mu \mathrm{m}$. Particle counts in each sub-range are binned into 15 equally spaced 
bins according to radii. These outputs were used to produce 20 min moving averages for each bin. Total aerosol concentrations, $N$, are obtained by integrating over all radii. Figure 1e illustrates the resulting time series of raw droplet concentrations measured during BREWEX.

The most striking features in this time series are multiple concentration peaks during YDs 116 and early 117, which are too high in magnitude to be correlated with the low to moderate winds observed for the same period (Fig. 1a and e). Meanwhile, measurements of $N$ collected during higher winds after YD 117 appear to follow the wind speed intensity. A combination of these observations with the airflow direction reversal mentioned earlier (Fig. 4 and Sect. 4.1) suggests that the air masses passing through FLIP's location on YDs 116 and early 117 might be contaminated by land and/or surf zone aerosol sources. This would interfere with the requirement of the dry deposition method for steady production flux over a period of hours or even days. In addition, considering that the goal of this study is to investigate the relationship between the SSA production flux and surface brightness temperature, it is necessary that all data be associated with clean air masses so that the effects of the local forcing (controlling) factors are captured. Therefore, droplet concentration measurements for YDs 116 and early 117 were discarded, and only samples of clean marine air with known 5-day back trajectories over the North Pacific were used. In the time frame useful for further analysis, from YD 117 to the end of the data collection, $N$ steadily increased from $\sim 7 \times 10^{4}$ to $2 \times 10^{5} \mathrm{~m}^{-3}$ as wind speed increased.

To remove the dependence of measured particle radius on ambient relative humidity, time-dependent RH measurements were used to convert the mean droplet radius of each bin to the corresponding dry radius, $r_{\mathrm{dry}}$, i.e., the radius of corresponding salt particle without water (for details on this conversion see Gerber, 1985, and Andreas, 2002). Mean radius within each bin was calculated on a logarithmic scale.

To obtain the surface flux using the dry deposition method, all measurements of droplet concentrations, $N(r)$, were converted to $10 \mathrm{~m}$ height reference using Eq. (3). The gravitational settling velocity was estimated with Eq. (2) using original non-dry radius, and the wind friction velocity was calculated by logarithmically extrapolating measured $U_{10}$ to the surface (Large and Pond, 1981). The sea spray surface flux at $10 \mathrm{~m}$ height, $F\left(r_{\text {dry }}\right)$, was then calculated using Eq. (1). Results of these calculations were binned by equally spaced logarithmic increments of dry radius and presented as flux per infinitesimal range of radii, $\mathrm{d} F(r) / \mathrm{d} \ln (r)$. Hereafter $r$ refers to $r_{\text {dry }}$ and "ln" refers to the natural logarithm.

Another output of the dry deposition method is the total surface flux integrated over all radii within the PMS measurement range, $F_{\mathrm{PMS}}$. The subscript of $F_{\mathrm{PMS}}$ points out that this quantity is dependent on the radii cutoff range specific to the PMS instrument (more specifically, the range $1.0 \mu \mathrm{m}<r<23.5 \mu \mathrm{m}$ was used to calculate $F_{\mathrm{PMS}}$ throughout this paper). Nonetheless, the total flux, $F_{\mathrm{PMS}}$, as opposed to

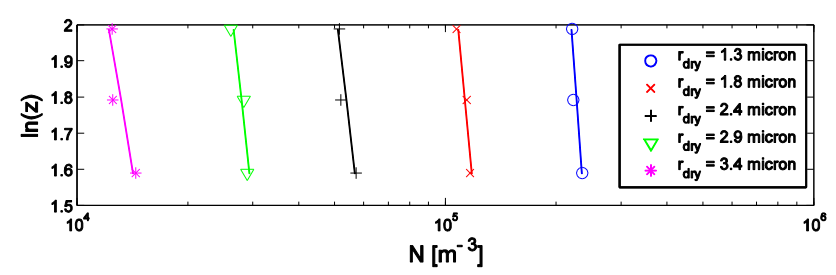

Figure 5. Vertical profiles of aerosol concentrations at five radii (symbols) and corresponding logarithmic fits (solid lines).

the size-resolved production flux, $\mathrm{d} F(r) / \mathrm{d} \ln (r)$, is useful to study the sensitivity of the SSA surface flux to radiometric brightness temperature, $T_{\mathrm{B}}$. Within the data subset where simultaneous brightness temperature and SSA flux data are available, use of the total surface flux in this analysis helps to compensate for the reduction in the aerosol data sample size due to limited simultaneous radiometer uptime.

In addition to the dry deposition method, estimates of the surface flux were obtained using the vertical gradient method (Sect. 2.1.1). To ensure the steady-state conditions required for measuring the vertical concentration profile, $N(z, r)$, with a single particle counter in vertical profiling mode, only one segment of $\sim 7 \mathrm{~h}$ (YDs 118.6 to 118.9) from all data collected was used. Within this segment, wind speed held relatively steady at $U_{10} \approx 11 \mathrm{~m} \mathrm{~s}^{-1}$. Concentration profiles were constructed based on data collected at three heights of 7.3, 6.0, and $4.9 \mathrm{~m}$. Three consecutive profiles were measured within this time frame, with sampling times at each level ranging from $30 \mathrm{~min}$ to $1 \mathrm{~h}$. Samples at each height were averaged to form one vertical profile for the entire $7 \mathrm{~h}$ segment. Additionally, only five radius bins (ranging from $\sim 1$ to $\sim 3.5 \mu \mathrm{m}$ ) were found to contain a sufficient number of samples suitable for profile fitting. Resulting $N(z, r)$ profiles (Fig. 5) were fitted with best-matching logarithmic curves to obtain $N_{*}(r)$ in Eq. (4). Consequently, Eq. (5) was used to calculate surface flux, which was then normalized by $\ln (r)$ to match the format and dimensions of the dry deposition method output. Note that the vertical deposition method provided only a few points at one wind speed. Therefore these points serve for reference and verification purposes but, unlike the output of the dry deposition method, are not sufficient for full quantitative parameterization.

\section{Results}

The main objective of this study is to investigate the relationship between aerosol production flux and microwave brightness temperature of the sea surface. In this section, we present the analysis of the collected aerosol and radiometric data (Fig. 1) in pursuit of this goal.

Figure 6 shows size-resolved sea spray source function $\mathrm{d} F(r) / \mathrm{d} \ln (r)$ (black circles) in terms of $r_{\mathrm{dry}}$ at four wind speeds obtained with the dry deposition method (Sects. 2.1.1 


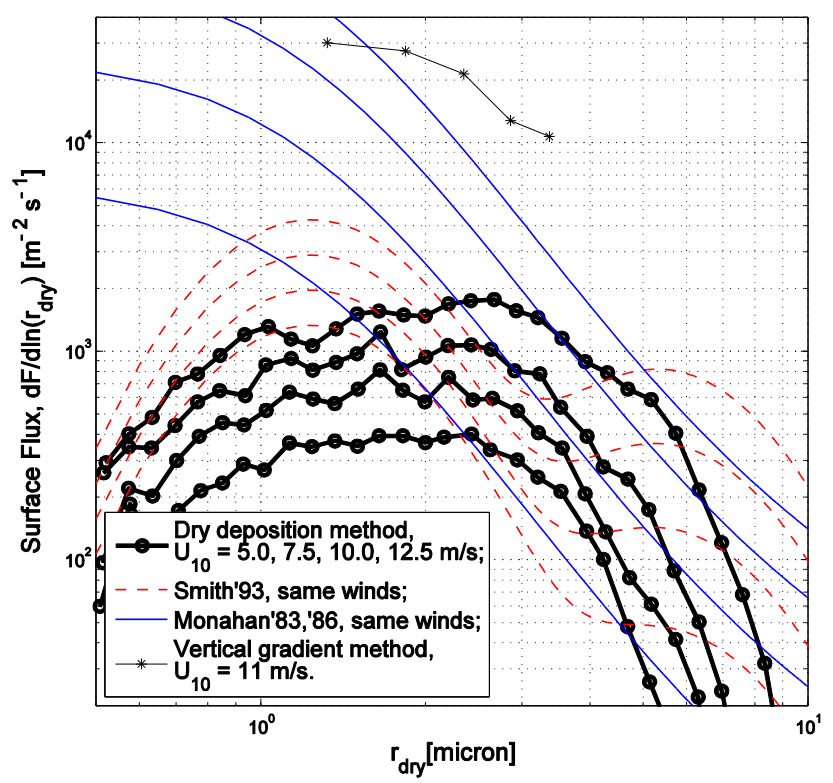

Figure 6. Parameterizations of SSA surface flux, obtained in this study (marked with symbols) and compared to past studies (solid or dashed lines), given as functions of dry radius and wind speed. Positions of curves with the same color and symbol are such that higher wind curves are always above lower wind curves.

and 4.3). Surface fluxes obtained with the vertical gradient method from the available data (see Sect. 4.3) are also shown in Fig. 6 (black asterisks). SSA fluxes obtained with the SSSFs of Monahan et al. (1986) (blue solid lines) and Smith et al. (1993) (red dashed lines) for the same wind speeds as for the dry deposition method provide additional comparisons.

The results of the vertical gradient method are approximately an order of magnitude higher than the results from the dry deposition method and those obtained with the parameterization of Smith et al. (1993). This difference is discussed further in Sect. 6.2. The overall shape of the Smith et al. (1993) parameterization agrees with the empirical fluxes calculated using the dry deposition method. The comparison with the parameterization based on the whitecap method (Monahan et al., 1983, 1986) shows agreement for larger droplets $\left(r_{\text {dry }}>\sim 2 \mu \mathrm{m}\right)$ and differences for smaller droplets, with the parameterization predicting much higher fluxes.

Figure 7 evaluates the sensitivity of the total SSA surface flux, $F_{\mathrm{PMS}}$ (Sect. 4.3), to various input parameters, such that the vertical axis values remain constant across all panels, but the horizontal axis changes depending on the chosen input parameter. In all four panels, individual data points (red and black dots) were obtained from the time series with $4 \mathrm{~s}$ sampling rate (Sect. 4.3) by first smoothing the time series by a 20 min moving average and then decimating them (for presentation clarity) by averaging over every 20 consecutive aerosol data points. Trends (solid black curves) are obtained by linearly connecting bin averages, where six equally
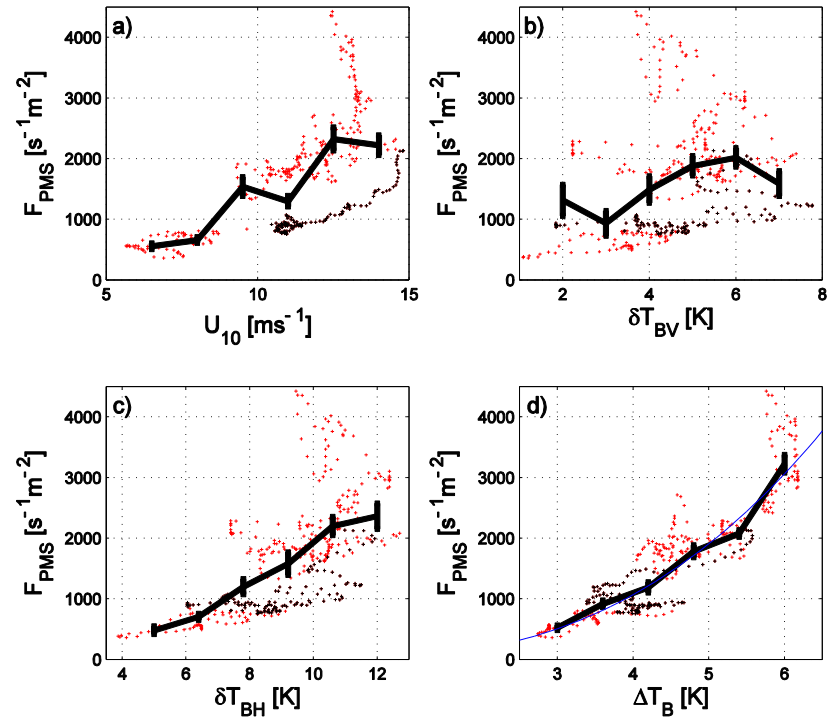

Figure 7. Total sea spray aerosol surface flux within the PMS instrument particle radius measurement range, plotted against each of four variables: (a) $U_{10}$, (b) $\delta T_{\mathrm{BV}}$, (c) $\delta T_{\mathrm{BH}}$, and (d) $\Delta T_{\mathrm{B}}$. Shown symbols represent all individual data points, while specifically black symbols highlight the subset corresponding to the YD 118.5-119.2 time frame. Solid black line connects equally spaced bin averages with shown $95 \%$ confidence intervals. Fitted thin blue curve in panel (d) is given by Eq. (14).

spaced bins are defined across the range of each input parameter. A $95 \%$ confidence interval is shown for each binaveraged point, calculated as $2 \sigma N_{\mathrm{S}}^{-1 / 2}$, where $\sigma$ is the standard deviation of the points in the bin and $N_{\mathrm{S}}$ is the number of samples in the bin. Figure 7a shows the wind speed dependence $F_{\mathrm{PMS}}\left(U_{10}\right)$, where $U_{10}$ was measured by the Vaisala meteorological station at $10 \mathrm{~m}$ height. This dependence is widely used to parameterize the surface flux but is known to have wide scatter, which is confirmed in the present figure. It is clear that the bin-averaged $F_{\mathrm{PMS}}\left(U_{10}\right)$ relationship alone is unable to completely capture the observed variability of the surface flux. For example, a group of outlier points is shown in black. This group corresponds to the data collected in the YD 118.5-119.2 time frame, during which the wind was rapidly growing (see Fig. 1a). During this time the wave field is still developing and is not expected to produce as many whitecaps, and hence aerosol, as a wave field in equilibrium with the corresponding wind speed, such as YD > 119.5. This difference in red and black populations illustrates the fundamental deficiency of the wind speed as a controlling parameter for SSA production parameterization. Below, we propose a different input parameter that does not have this deficiency, is directly sensitive to the local production of SSA, and is able to collapse black and red populations on a single curve.

In a quest for a better correlation between SSA surface flux and a local sea state parameter, we investigated relationships 


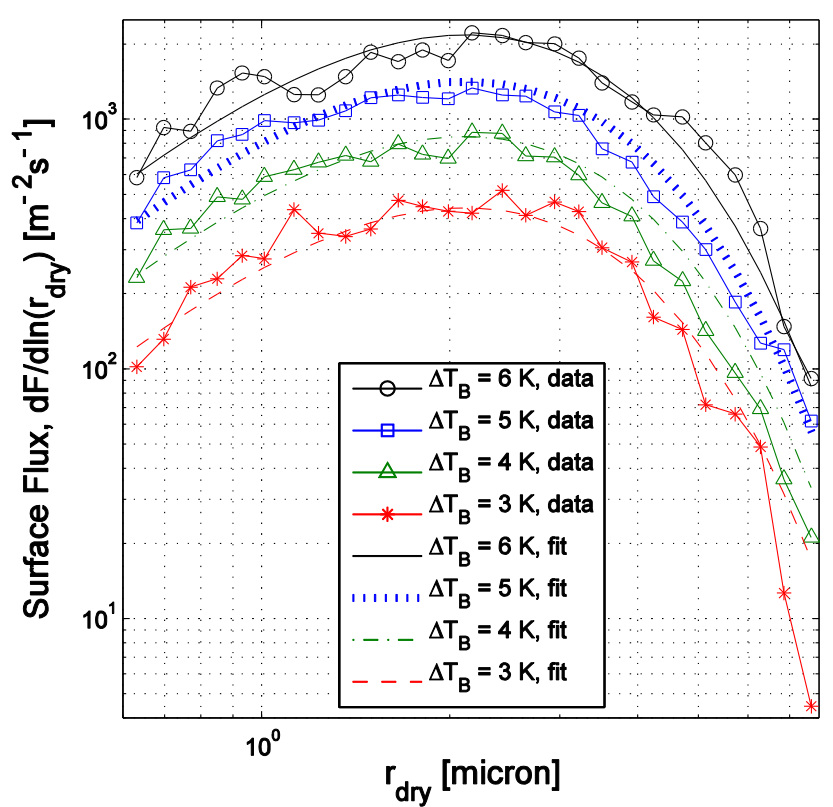

Figure 8. Surface flux parameterization with $U_{10}$ replaced by $\Delta T_{\mathrm{B}}$. Symbols represent data points given in Table 1, and corresponding fitted curves are given by Eq. (13).

between $F_{\mathrm{PMS}}$ and $\delta T_{\mathrm{BH}}, \delta T_{\mathrm{BV}}$, and $\Delta T_{\mathrm{B}}$ (see Sect. 4.2), shown in Fig. 7b, c, and d, respectively. The most important feature demonstrated by Fig. 7 is that the parameter $\Delta T_{\mathrm{B}}$ appears to be capable of capturing $F_{\mathrm{PMS}}$ variability better than wind speed, $U_{10}$. In fact, the relationship between $F_{\mathrm{PMS}}$ and $\Delta_{\mathrm{TB}}$ is characterized by less scatter, better smoothness, and greater sensitivity than that between $F_{\text {PMS }}$ and $U_{10}$. The instantaneous values (red and black dots in Fig. 7) are grouped closer together around their respective bin averages in $F_{\mathrm{PMS}}\left(\Delta T_{\mathrm{B}}\right)$ than in $F_{\mathrm{PMS}}\left(U_{10}\right)$, resulting in tighter $95 \%$ confidence intervals. The trend of the relationship $F_{\mathrm{PMS}}\left(\Delta T_{\mathrm{B}}\right)$ is more consistent and monotonic than that of $F_{\mathrm{PMS}}\left(U_{10}\right)$ dependence (thick solid lines in Fig. 7a and d). Finally the sensitivity of $F_{\mathrm{PMS}}$ to these different values may be compared by calculating the range of variation $\left(F_{\max }-\right.$ $\left.F_{\min }\right)$ in the bin-averaged values over the full dynamic range for each parameter observed during the experiment. The resulting quantification demonstrates a significant advantage for $\Delta T_{\mathrm{B}}$ :

$$
\begin{aligned}
& \left.\left(F_{\max }-F_{\min }\right)\right|_{U_{10}}=1771\left[\mathrm{~s}^{-1} \mathrm{~m}^{-2}\right], \\
& \left.\left(F_{\max }-F_{\min }\right)\right|_{\delta T_{\mathrm{BV}}}=1087\left[\mathrm{~s}^{-1} \mathrm{~m}^{-2}\right], \\
& \left.\left(F_{\max }-F_{\min }\right)\right|_{\delta T_{\mathrm{BH}}}=1883\left[\mathrm{~s}^{-1} \mathrm{~m}^{-2}\right], \\
& \left.\left(F_{\max }-F_{\min }\right)\right|_{\Delta T_{\mathrm{B}}}=2706\left[\mathrm{~s}^{-1} \mathrm{~m}^{-2}\right] .
\end{aligned}
$$

In other words, SSA surface flux was found to be the least sensitive to $\delta T_{\mathrm{BV}}$; slightly more sensitive to $\delta T_{\mathrm{BH}}$ than to $U_{10}$; and by far the most sensitive to $\Delta T_{\mathrm{B}}$, specifically 1.53 times more so than $U_{10}$ over the observed range of conditions.
Table 1. Similar to Fig. 8, the table shows sea spray aerosol surface flux, $\mathrm{d} F / \mathrm{d} \ln \left(r_{\text {dry }}\right)$, as a function of dry radius, $r_{\text {dry }}$, and brightness temperature polarization difference, $\Delta T_{\mathrm{B}}$. Brightness temperature

\begin{tabular}{|c|c|c|c|c|}
\hline \multirow[b]{2}{*}{$r_{\text {dry }}[\mu \mathrm{m}]$} & \multicolumn{4}{|c|}{$\mathrm{d} F / \mathrm{d} \ln \left(r_{\mathrm{dry}}\right)\left[\mathrm{m}^{-2} \mathrm{~s}^{-1}\right]$} \\
\hline & $\Delta T_{\mathrm{B}}=3 \mathrm{~K}$ & $\Delta T_{\mathrm{B}}=4 \mathrm{~K}$ & $\Delta T_{\mathrm{B}}=5 \mathrm{~K}$ & $\Delta T_{\mathrm{B}}=6 \mathrm{~K}$ \\
\hline 0.51 & 35 & 212 & 290 & 299 \\
\hline 0.58 & 118 & 360 & 324 & 509 \\
\hline 0.63 & 102 & 232 & 384 & 583 \\
\hline 0.70 & 132 & 361 & 583 & 926 \\
\hline 0.77 & 212 & 366 & 627 & 894 \\
\hline 0.85 & 229 & 489 & 819 & 1334 \\
\hline 0.93 & 284 & 479 & 870 & 1530 \\
\hline 1.01 & 276 & 588 & 988 & 1481 \\
\hline 1.13 & 434 & 629 & 968 & 1256 \\
\hline 1.23 & 349 & 673 & 992 & 1251 \\
\hline 1.36 & 339 & 717 & 1082 & 1480 \\
\hline 1.50 & 363 & 678 & 1220 & 1853 \\
\hline 1.66 & 473 & 797 & 1249 & 1700 \\
\hline 1.81 & 447 & 723 & 1224 & 1893 \\
\hline 1.99 & 427 & 696 & 1206 & 1716 \\
\hline 2.17 & 420 & 886 & 1334 & 2217 \\
\hline 2.43 & 518 & 878 & 1250 & 2163 \\
\hline 2.65 & 412 & 712 & 1239 & 2024 \\
\hline 2.95 & 466 & 707 & 1071 & 2002 \\
\hline 3.22 & 427 & 597 & 1036 & 1752 \\
\hline 3.51 & 306 & 463 & 762 & 1396 \\
\hline 3.92 & 268 & 409 & 674 & 1173 \\
\hline 4.24 & 161 & 272 & 490 & 1040 \\
\hline 4.72 & 144 & 225 & 388 & 1022 \\
\hline 5.14 & 72 & 142 & 300 & 803 \\
\hline 5.73 & 66 & 97 & 185 & 597 \\
\hline 6.29 & 49 & 69 & 127 & 365 \\
\hline 6.85 & 13 & 36 & 119 & 148 \\
\hline 7.58 & 4 & 21 & 62 & 91 \\
\hline 8.30 & 0 & 6 & 19 & 54 \\
\hline 9.14 & 0 & 3 & 8 & 47 \\
\hline 10.00 & 0 & 4 & 5 & 0 \\
\hline 11.09 & 0 & 0 & 0 & 0 \\
\hline 12.14 & 0 & 0 & 0 & 0 \\
\hline
\end{tabular}
polarization difference has been binned to the nearest K. For reference, $\Delta T_{\mathrm{B}}=3,4,5,6[\mathrm{~K}]$ corresponds to $U_{10}=5.4,8.4,12.0$, $16.8 \mathrm{~m} \mathrm{~s}^{-1}$.

For these reasons, brightness temperature polarization difference, $\Delta T_{\mathrm{B}}$, emerges as a sensitive and robust input parameter for estimating SSA surface flux, superior to the wind speed, $U_{10}$, or any other parameter tested here. This result is the key finding of this study. The central practical question then is the feasibility of replacing $U_{10}$ with $\Delta T_{\mathrm{B}}$ so that the SSA surface flux is parameterized as $\mathrm{d} F\left(r, \Delta T_{\mathrm{B}}\right) / \mathrm{d} \ln (r)$. Figure 8 and Table 1 demonstrate the utility of parameterizing SSA production flux in terms of brightness temperature polarization difference, as opposed to the conventional parameterizations shown in Fig. 6. 

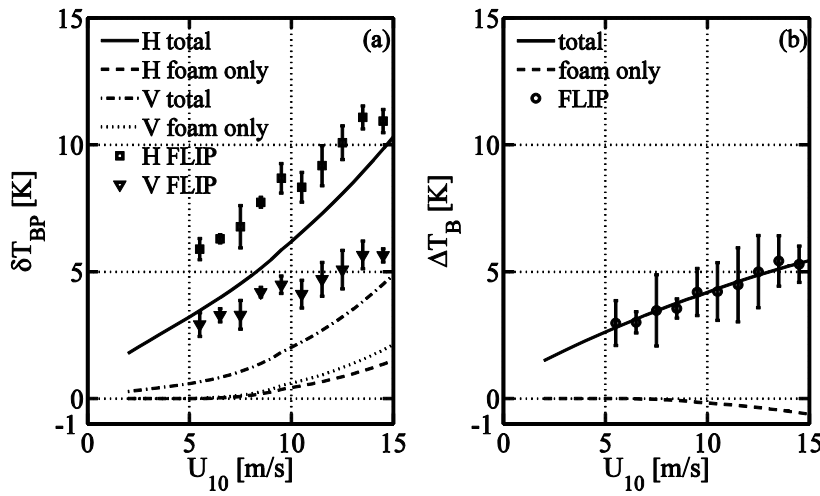

Figure 9. Brightness temperature comparison between FLIP observations and H12 model output. Panel (a) compares horizontal and vertical polarizations separately, and panel (b) compares their difference. Both panels show total values (foam + roughness), as well as the foam-only component. Error bars show 1 standard deviation for data within each bin.

\section{Discussion}

The discussion in this section aims to understand the physical meaning of the parameter $\Delta T_{\mathrm{B}}$ in relation to aerosol production, make our case for using brightness temperature as an input variable for SSA surface flux parameterization, and lay initial groundwork for potential satellite remote sensing applications. Using the H12 model, we explore and interpret the physical meaning of the parameter $\Delta T_{\mathrm{B}}$ and propose an explanation for its relevance to the SSA surface flux (Sect. 6.1). We use the background information (Sect. 2) and our results (Sect. 5) to discuss existing uncertainties that ultimately motivate us to seek new alternative parameterizations (Sect. 6.2). We propose an empirical approach based on $\Delta T_{\mathrm{B}}$, which reduces some of these uncertainties (Sect. 6.3). A discussion of the applicability of the proposed empirical approach for direct satellite remote sensing of SSA production flux follows (Sect. 6.4).

\subsection{Physical interpretation of $\Delta T_{B}$ parameter}

The H12 model (Sect. 2.2.4) can be used to interpret the parameters derived from the brightness temperature. Of specific interest are the wind-induced parameters $\delta T_{\mathrm{BH}}$ and $\delta T_{\mathrm{BV}}$, which contain contributions from both roughness and foam on the water surface; i.e., $\delta T_{\mathrm{BP}}=T_{\mathrm{BrP}}+T_{\mathrm{BfP}}$ (Eqs. $8 \mathrm{~b}$ and 9). These are shown in Fig. 9a as functions of wind speed, $U_{10}$. The model calculates the contributions of surface roughness and foam separately. The modeled contribution of the foam term is also shown in Fig. 9a. The difference $\delta T_{\mathrm{BP}}-T_{\mathrm{BfP}}=$ $T_{\mathrm{BrP}}$ can be considered the contribution arising only from surface roughness (not plotted to avoid cluttering).

The curves in Fig. 9a have a number of features significant for further discussion. First, comparison of $\delta T_{\mathrm{BH}}$ and $\delta T_{\mathrm{BV}}$ (solid and dash-dotted curves) exhibits the expected behav- ior that radiometric data at $H$ polarization are more sensitive to sea state changes than those at $V$ polarization, a result consistent with that seen in Fig. 7c and b (Sect. 5). Second, the presence of foam (dashed and dotted curves) becomes noticeable for wind speed above $\sim 7 \mathrm{~m} \mathrm{~s}^{-1}$ (also expected), and absolute foam contributions at $H$ and $V$ polarizations are of similar magnitude. The $\mathrm{H} 12$ model suggests that relative contributions of roughness and foam at $V$ polarization are of comparable magnitude (as seen at $U_{10}=15 \mathrm{~m} \mathrm{~s}^{-1}$ ), whereas the $H$ polarization signature is dominated by surface roughness.

In addition to modeled curves, Fig. 9a shows $\delta T_{\mathrm{BP}}$ obtained from measured values via Eq. (9) (squares and triangles). These are the same data as shown in Fig. $7 \mathrm{~b}$ and c, only bin-averaged by wind speed, $U_{10}$. Ideally, the model output (solid and dash-dotted curves) is expected to match observations (the symbols); however it does not, mostly due to an apparent $\sim 2-3 \mathrm{~K}$ constant offset in both polarizations. Such "DC offset" is a common problem in the processing of field measurements (Hollinger, 1971; Swift, 1974; Camps et al., 2004) and can be caused by a number of reasons related to choice of radiometer calibration procedure, choice of model for the flat sea surface term $\delta T_{\mathrm{B} 0 \mathrm{P}}$, and reflection of unknown (cloud-dependent) atmospheric radiation from the water surface. Regardless of origin, the offset approximately cancels out when the difference between the two polarizations is taken (Eq. 10). As a result, there is a near-perfect match between the model output and parameter $\Delta T_{\mathrm{B}}$ calculated from field measurements (Fig. 9b). Note that it is possible that the same noise-cancelling property is partially responsible for making $\Delta T_{\mathrm{B}}$ a better and more robust parameter than $\delta T_{\mathrm{BH}}$ for parameterizing SSA surface flux, as demonstrated in Fig. 7.

The separation of modeled brightness temperatures into roughness and foam components in the $\mathrm{H} 12$ model allows for some physical interpretation of the $\Delta T_{\mathrm{B}}$ parameter. Because the foam contributions for $H$ and $V$ polarizations are similar (Fig. 9a), they mostly cancel out within $\Delta T_{\mathrm{B}}$ and become a negligibly small part of the total signal (Fig. 9b). The main contribution to $\Delta T_{\mathrm{B}}$ in Fig. $9 \mathrm{~b}$ is, therefore, from the surface roughness. This suggests that a parameter dependent on roughness and independent of foam serves as the best indicator of aerosol production. Such a result has intriguing implications for the interpretation of the SSA production.

Usually the SSA production is associated with the whitecap fraction on the ocean surface, which is the main premise of the whitecap method. Unlike bursting bubbles within whitecaps, surface roughness does not directly cause aerosol production, making the suggested interpretation counterintuitive. While this experiment was not designed to resolve this question definitively, we can hypothesize an underlying physical reason for the apparently dominant importance of the surface roughness by considering the active and passive phases of breaking waves separately. The wave-breaking process is known to significantly enhance surface roughness 
near steep and actively breaking wave crests (Cox, 1958; Longuet-Higgins, 1963, 1992), which contributes to the observed wind speed sensitivity of microwave scattering and emission. This allows the interpretation of parameters which are primarily sensitive to roughness, i.e., $\delta T_{\mathrm{BH}}$ (in Fig. 9a) and $\Delta T_{\mathrm{B}}$ (in Fig. $9 \mathrm{~b}$ ), as measures of the surface area and intensity of the active phases of breaking waves. Surface foam, on the other hand, exists not only in active but also in the passive phases of wave breaking and covers much larger areas (Monahan, 1990). Therefore, since $\delta T_{\mathrm{BV}}$ has a comparable level of sensitivity to roughness as to foam (as shown in Fig. 9a), it can be interpreted as responding to both the active and passive phases of breaking waves.

It is surmised that parameters related purely to the active phase (i.e., $\delta T_{\mathrm{BH}}$ and $\Delta T_{\mathrm{B}}$ ) serve as good indicators of aerosol production for two reasons. First, the intensity of the active phase of wave breaking might be a better indicator of the amount of bubbles produced that burst later during the passive phase. Second, the amount of aerosol produced during the active phase might be larger than during the passive phase. This could happen within a smaller surface area of the active phase due to much shorter bubble lifetime between generation and burst, and also due to a more likely advection of droplets by the airflow upwards from the top of wave crests. Unfortunately, the existing literature does not quantify the aerosol production rate difference between active and passive phases of breaking waves, thus motivating further research in this area. Meanwhile, we proceed using the $\Delta T_{\mathrm{B}}$ parameter under the assumption of its direct relevance to the sea surface processes responsible for SSA production.

\subsection{Existing measurement and parameterization uncertainties}

A 1-order-of-magnitude difference between size-resolved SSA fluxes measured with the dry deposition and the vertical gradient methods (Fig. 6) shows how much the choice of measuring technique or methodology can influence the results. A similar difference was observed by Petelski and Piskozub (2006) between their SSA surface flux estimates based on the vertical gradient method and the Smith et al. (1993) parameterization. This difference observed in the present experiment and that of Petelski and Piskozub suggests that the reasons for these differences are more fundamental than a mere measurement error or a difference in data filtering and processing techniques.

The difference between the results of the dry deposition and the vertical gradient methods is, in fact, a good example of the large uncertainties that occur by starting with a different set of assumptions and simplifications for the boundary layer physics when estimating the surface flux (Sect. 2.1.1). As was discussed earlier, the dry deposition method could underestimate the SSA flux, particularly for smaller radii, while the vertical gradient method likely overestimates the flux because of the assumption of passive tracer-like aerosol behavior. The similarity theory expects a constant flux across the vertical profile, but the effect of the gravitational droplet settling is such that the flux decays with height and becomes significantly smaller at $10 \mathrm{~m}$ above MWL, particularly for particles with larger radii.

Further, the uncertainties inherent in the flux estimation are compounded when these data are used to develop parameterizations for predicting SSA surface flux. Usually, physics-based, as opposed to empirical, approaches are employed for such SSA surface flux parameterizations, because the physical approaches allow processes controlling the SSA production to be recognized and modeled explicitly. However, physical approaches come with their own sets of assumptions and simplifications (Sect. 2.1.2) which are difficult to verify. For example, the validity of the assumption of variable separation (see Sect. 2.1.2) has not been verified empirically; however, it is expected not to hold when one carefully examines the results of Smith et al. (1993) or Petelski and Piskozub (2006), both giving some evidence of a more complex shape of the empirical function $\mathrm{d} F\left(r, U_{10}\right) / \mathrm{d} r$. In addition to the assumption of the shape-magnitude separation, the whitecap method - the most direct and widely used method of observing and parameterizing the SSA production - relies on the assumptions of (i) proportionality between $W$ and SSA production and (ii) similarity between aerosol production by laboratory and by open-ocean whitecaps, both of which add an unknown uncertainty. Finally, a common assumption that the magnitude of total SSA production can be sufficiently controlled by the local wind speed, $U_{10}$, is often made for convenience and is not expected or observed to hold.

Difficulties outlined above motivate continued search for alternative approaches that would eliminate or reduce existing uncertainties. The new parameterization method proposed below is empirical rather than physical in nature. Its primary advantage is in the choice of inherently more appropriate input parameters, which leads to the reduction of uncertainties caused by weak physical assumptions.

\subsection{Empirical parameterization of sea spray aerosol flux}

The brightness temperature and derived combinations of brightness temperatures at different polarizations are sensitive to the sea state under various conditions and have been successfully used to obtain a number of basic geophysical parameters (Sect. 2.2.1). Figure 7d and Eq. (11) provide strong quantitative evidence that the polarization brightness temperature difference, $\Delta T_{\mathrm{B}}$, is a good predictor of the SSA flux. It can be used, therefore, in place of a physical forcing variable to parameterize SSA production.

Such parameterization can be formulated in a number of ways. In the most general form, a continuous parameterization function, $F\left(r_{\text {dry }}, \Delta T_{\mathrm{B}}\right)$, should be constructed, similar to $F\left(r_{\text {dry }}, U_{10}\right)$ shown in Fig. 6 . Building such a function 
with the available limited sample size requires some simplifications, such as the separation-of-variables assumption, i.e.,

$\mathrm{d} F / \mathrm{d} \ln \left(r_{\mathrm{dry}}\right)=f\left(\Delta T_{\mathrm{B}}\right) \cdot g\left(r_{\mathrm{dry}}\right)$,

where $f(\cdot)$ is a function of sea state represented by the $\Delta T_{\mathrm{B}}$ parameter, and $g(\cdot)$ is a radius-dependent shape function, independent of the sea state. After an arbitrary pick of an appropriately shaped analytical function and optimization of its empirical coefficients, we arrive at

$\mathrm{d} F / \mathrm{d} \ln \left(r_{\mathrm{dry}}\right)=A \cdot \Delta T_{\mathrm{B}}^{n} \cdot r_{\mathrm{dry}}^{k} \exp \left(-r_{\mathrm{dry}} / r_{0}\right)$,

where $A=65\left[\mathrm{~K}^{-n} \mu \mathrm{m}^{-\mathrm{k}} \mathrm{m}^{-2} \mathrm{~s}^{-1}\right], n=2.3, k=2.5$, and $r_{0}=0.85[\mu \mathrm{m}]$ are empirical constants with dimensions chosen such that the left-hand side of Eq. (13) has a $\left[\mathrm{m}^{-2} \mathrm{~s}^{-1}\right]$ dimension, while $r_{\text {dry }}$ maintains the $[\mu \mathrm{m}]$ dimension. The result of the Eq. (13) empirical fit is compared to available data points in Fig. 8.

The empirical constants above were obtained in two steps. First, the best match was found between the radiusdependent part of the analytical function and the surface flux curve averaged over all $\Delta T_{\mathrm{B}}$. Next, each of the four data curves in Fig. 8 (and Table 1) was averaged over all radii to find the optimal dependence on $\Delta T_{\mathrm{B}}$. Note that for the above calculations, data presented in Table 1 were truncated on both ends. The first two rows in Table 1 were removed due to concerns that the PMS instrument underestimates particle concentrations in this range (Reid et al., 2006). The last five rows were removed because the small number of droplets registered in this range was insufficient to form a statistically significant sample. Therefore, the parameterization in Eq. (13) and all data and fitted curves presented in Fig. 8 are based on data in the range of $r_{\text {dry }}=(0.63$ to 7.58$) \mu \mathrm{m}$.

The parameterization given in Eq. (13) has its limitations and is intended as a first step towards constructing the $F\left(r_{\text {dry }}, \Delta T_{\mathrm{B}}\right)$ function, rather than a final product. First, the amount of simultaneous and collocated data where both SSA and $T_{\mathrm{B}}$ measurements are available is limited, particularly for larger droplets. Second, the separation-of-variables assumption (Eq. 12) is made mostly for convenience and to compensate for the small data sample size, and it does not have strong physical reasoning behind it. Contrarily, as weather conditions become rougher, large-droplet production is expected to grow faster. Some signs of that effect can be seen in Fig. 8 (i.e., the sharp drop-off of large-droplet production in the calmest case with $\Delta T_{\mathrm{B}}=3 \mathrm{~K}$ ). However, the separation of variables forces a fixed radius-dependent shape and, therefore, does not allow the capture of this effect. In future studies, as more data become available to complement the data in Table 1, it will become possible to construct a more complex and realistic $F\left(r_{\mathrm{dry}}, \Delta T_{\mathrm{B}}\right)$ function.

If an aerosol modeling application does not require a sizeresolved source function, a more robust bulk parameterization can be obtained using the total $F_{\mathrm{PMS}}\left(\Delta T_{\mathrm{B}}\right)$ dependence.
By fitting the best-matching curve through the data presented in Fig. 7d (thin solid line), we find the following expression:

$F_{\mathrm{PMS}}=a\left(\Delta T_{\mathrm{B}}\right)^{m}$,

where $a=29\left[{ }^{\circ} \mathrm{K}^{-m} \mathrm{~m}^{-2} \mathrm{~s}^{-1}\right]$ and $m=2.6$ are empirical constants (Eq. 14 is shown in Fig. 7d). When using this result, it is important to keep in mind that it is sensitive to the specific radius detection range of the PMS instrument (Sects. 3.2 and 4.3). Unlike the derivation of Eq. (13), in this case the entire range of $r_{\text {dry }}$ shown in Table 1 was used without truncation. Note that $n \neq m$ because calculations of the best fit to Eq. (14) were done for a sum of droplets measured across the measured radius range, effectively giving preference to droplets with more commonly occurring radii, whereas in calculations for Eq. (13) all radii shown in Fig. 8 were given equal weight.

Under the assumption of variable separation (Eq. 12) and provided appropriate normalizations are applied, one can combine Eq. (14) or the $\Delta T_{\mathrm{B}}$-dependent term of Eq. (13) with a radius-dependent shape function obtained from a different source (e.g., de Leeuw et al., 2011). This modification can potentially remove a concern (see Reid et al., 2006) regarding correct estimates of particle radii registered by the PMS forward-scattering spectrometer used in this study. Moreover, the benefits of replacing wind speed, $U_{10}$, with the $\Delta T_{\mathrm{B}}$ parameter, which essentially is the central finding of this paper, can be exploited within SSA production parameterizations obtained completely independently of this study. This option may be particularly attractive in cases where a wind-speed-dependent parameterization is based on field measurements of SSA surface flux using a different methodology, which may be superior to the dry deposition method employed in this study. In this case, instead of using Eqs. (13) or (14), it might be beneficial to simply replace $U_{10}$ with $\Delta T_{\mathrm{B}}$ using the following relationship:

$\Delta T_{\mathrm{B}}=-0.0071 \cdot U_{10}^{2}+0.4253 \cdot U_{10}+0.6692$,

which fits the modeled $\Delta T_{\mathrm{B}}\left(U_{10}\right)$ relationship shown in Fig. 9b. Note that, given the excellent agreement between the H12 model and observations for this relationship, a wider range of model output was used to form the polynomial given in Eq. (15), which extends wind speed applicability limits to $U_{10}=(2$ to 22$) \mathrm{m} \mathrm{s}^{-1}$. An interesting sidenote at this point is that Eqs. (14) and (15) suggest a $F_{\mathrm{PMS}} \sim U_{10}^{1.7}$ proportionality in the studied range, which is somewhat in agreement with radiometrically observed whitecap fraction power laws (Salisbury et al., 2013). The next step would be to use the relationship given in Eq. (15) by applying it to $U_{10}$-dependent parameterization given, for example, by Smith et al. (1993). Then their Eq. (7) becomes

$\log \left(A_{1}\right)=0.0273 \Delta T_{\mathrm{B}}^{2}+0.0330 \Delta T_{\mathrm{B}}+2.4768$,
$\log \left(A_{1}\right)=0.0050 \Delta T_{\mathrm{B}}^{2}+0.5463 \Delta T_{\mathrm{B}}-0.8470$. 
Keeping the rest of their parameterization untouched, one can arrive at the sea spray production parameterization free of wind speed dependence. This approach effectively leaves the parameterization unchanged on average; however it is likely to improve the SSA production estimate accuracy in situations where $\Delta T_{\mathrm{B}}$ deviates from its mean value for a given wind speed, e.g., such as shown with black points in Fig. 7a.

\subsection{Towards satellite remote sensing of sea spray aerosol production}

The derived empirical relationship between the surface flux and brightness temperature polarization difference has useful implications for remote sensing of SSA production. First, $\Delta T_{\mathrm{B}}$ is a variable that well characterizes the sea state when both surface roughness and whitecaps from breaking waves are present. It could be useful as a forcing variable for a wide range of conditions in the ocean as suggested by its usefulness for parameterizing SSA flux in terms of more relevant input variables (Sect. 2.1.3). Next, the availability of a reliable empirical relationship $F\left(\Delta T_{\mathrm{B}}\right)$ can provide reference estimates of SSA production when developing more physically based parameterizations. Finally, a capability to obtain SSA flux from available radiometric satellite observations will provide observations of SSA production on a global scale.

The primary variable needed for the proposed empirical parameterization is $\Delta T_{\mathrm{B}}$, defined by Eq. (10). This variable is readily available from existing or future dual-polarimetric microwave satellite sensors - e.g., WindSat, SSMIS, AMSR2 , and GMI - which in combination provide sufficient spatial resolution and revisit time (i.e., $\sim 4$ revisits per day with $\sim 30 \mathrm{~km}$ pixel size) on the global scale to match grid requirements of global aerosol models, such as the Navy Aerosol Analysis and Prediction System. The $\Delta T_{\mathrm{B}}$ parameter is obtained at the top of the atmosphere of the ocean surface, thus atmospheric contribution has to be removed from the measured TOA signal before it can be used. This contribution is primarily a function of precipitable water vapor and cloud liquid water within the atmospheric column, which are calculated, for example, as a part of WindSat retrieval algorithm.

Various sensors use different incidence angles, and Fig. 10 shows modeled $\Delta T_{\mathrm{B}}$ for an incidence angle, $\theta$, of $45^{\circ}$ (this study) and at other $\theta$ more typical of satellite measurements, e.g., 50, 53, and $55^{\circ}$. Within the studied range of parameters, conversions can be made using simple linear fits to the relationships between $\Delta T_{\mathrm{B} 45}, \Delta T_{\mathrm{B} 50}, \Delta T_{\mathrm{B} 53}$, and $\Delta T_{\mathrm{B} 55}$, shown in Fig. 10b:

$$
\begin{aligned}
& \Delta T_{\mathrm{B} 50}=1.40 \cdot \Delta T_{\mathrm{B} 45}+0.12, \\
& \Delta T_{\mathrm{B} 53}=1.58 \cdot \Delta T_{\mathrm{B} 45}+0.64, \\
& \Delta T_{\mathrm{B} 55}=1.96 \cdot \Delta T_{\mathrm{B} 45}+0.36 .
\end{aligned}
$$

As incidence angle increases over this range, the sensitivity of the $\Delta T_{\mathrm{B} \theta}$ parameter increases (Fig. 10a), and nearly
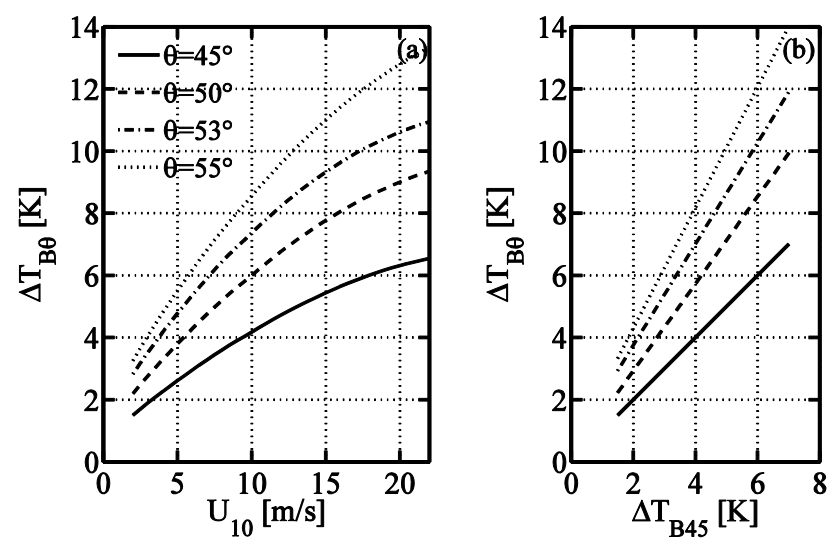

Figure 10. Expected values of the brightness temperature polarization difference, $\Delta T_{\mathrm{B}}$, at various incidence angles, $\theta$, based on $\mathrm{H} 12$ model. Panel (a) gives dependence of $\Delta T_{\mathrm{B}}$ on wind speed, $U_{10}$, at four different angles, $\theta$; panel (b) gives corresponding dependencies on $\Delta T_{\mathrm{B}}$ at $\theta=45^{\circ}$.

doubles between 45 and $55^{\circ}$ (see Eq. 17c), thus resulting in a potential reduction in the uncertainty of the surface flux estimate. For example, using the slope of the fit given in Eq. (14), which is based on Fig. 7d, if the retrieved value of $\Delta T_{\mathrm{B} 45}=5 \mathrm{~K}$ with a $0.5 \mathrm{~K}$ uncertainty, that would translate into $\sim 25 \%$ uncertainty in the estimate of the surface flux, $F_{\text {PMS }}$. However, if the brightness temperatures are measured at an incidence angle of $\theta=55^{\circ}$, the same $0.5 \mathrm{~K}$ uncertainty in $\Delta T_{B 55}$ would result in an uncertainty of $\sim 12.8 \%$, i.e., reducing the uncertainty of the surface flux estimate by half. Therefore, provided the retrieval uncertainty remains constant, the model suggests that it is beneficial to retrieve the $\Delta T_{\mathrm{B}}$ parameter at higher incidence angles.

It is likely that $\Delta T_{\mathrm{B}}$ measured at microwave frequencies other than the $10.7 \mathrm{GHz}$ (used throughout this study) can be useful for retrieving $\Delta T_{\mathrm{B}}$ at the ocean surface and, ultimately, for the SSA production estimates. Although the H12 model allows recalculation of $\Delta T_{\mathrm{B}}$ at other frequencies, since our results were only validated at $f=10.7 \mathrm{GHz}$, conversion to other frequencies was deemed premature within this paper.

Finally, present results do not take into consideration the effect of azimuthal angle on $\Delta T_{\mathrm{B}}$ (see Appendix for details). Therefore, retrieval of the wind vector from WindSat or an atmospheric circulation model can allow for additional correction based on azimuthal angle parameterization leading to further reduction in uncertainty.

\section{Conclusions}

This paper describes an experiment during which aerosol concentrations with radii ranging from 0.25 to $23.5 \mu \mathrm{m}$ and the surface brightness temperature, $10.7 \mathrm{GHz}$, were measured among other parameters. To the best of our knowledge, this is the first time such collocated and simultaneous 
measurements have been collected in the open ocean. An empirical relationship between parameters derived from these two time series has been developed and presented. This relationship (Figs. 7, 8; Eqs. 13, 14) suggests that a brightnesstemperature-derived parameter, $\Delta T_{\mathrm{B}}$, may be a better parameter than $U_{10}$ for the empirical parameterization of the rate of aerosol production at the ocean surface. Figure 7 demonstrates the significant improvement over the traditionally used wind speed, $U_{10}$. Section 6 provides a discussion of possible underlying physical bases for this outcome and points towards practical applications, such as the retrieval of aerosol production from satellite radiometric data. Some of the main uncertainties and shortcomings that are out of the scope of the current work but which must be addressed in any transition of this technique to operational use are (i) imperfections of aerosol production estimate methods (see Sect. 6.2), (ii) limited sample size used to construct the empirical relationships (Eqs. 13 and 14) in this study, and (iii) the necessity to accurately remove the atmospheric component of $\Delta T_{\mathrm{B}}$ measured by a satellite. 


\section{Appendix A}

In Sect. 2.2.4, we introduced the H12 model for the ocean surface emissivity, $e_{\mathrm{P}}$, and corresponding brightness temperature, $T_{\mathrm{BP}}$, developed by Hwang (2012). We use the H12 model in Sect. 6.1 to interpret the results in Sect. 5. Because the $\mathrm{H} 12$ approach given with Eq. (8b) differs somewhat from the general concept of $T_{\mathrm{BP}}$ modeling given with Eq. (7), we provide additional clarifications in this Appendix.

The contribution of each term $T_{\mathrm{BOP}}, T_{\mathrm{BrP}}$, and $T_{\mathrm{BfP}}$ in Eq. (7) to the total signal, $T_{\mathrm{BP}}$, is explicitly weighted by the whitecap fraction, $W$. In $\mathrm{H} 12$, terms $\delta T_{\mathrm{BrP}}$ and $\delta T_{\mathrm{BfP}}$ represent increases to $T_{\mathrm{B} 0 \mathrm{P}}$, incorporating weighting factors implicitly in the models used to obtain $\delta e_{\mathrm{rP}}$ and $\delta e_{\mathrm{fP}}$. The modeling of foam emissivity in $\mathrm{H} 12$ demonstrates how this implicit weighting is made.

The polarized foam emissivity, $e_{\mathrm{fP}}(P=H$ or $V$ polarization), is computed in the H12 model with the Fresnel formula using the dielectric constant of sea foam, $\varepsilon_{\mathrm{f}}$. The H12 model uses the quadratic mixing rule following the analysis of Anguelova (2008),

$\varepsilon_{\mathrm{f}}=\left[f_{\mathrm{a}}+\left(1-f_{\mathrm{a}}\right) \varepsilon^{1 / 2}\right]^{2}$,

where $f_{\mathrm{a}}$ is the void fraction of sea foam (defined as the content of air in a unit volume of air-water mixture) and $\varepsilon$ is the dielectric constant of seawater. The H12 model approximates $f_{\mathrm{a}}$ with whitecap fraction, $W$, while $W$ is estimated with the parameterization developed by Callaghan et al. (2008). The use of $W$ as a proxy for $f_{\mathrm{a}}$ in $\mathrm{H} 12$ is the assumption that provides $\delta e_{\mathrm{fP}}=W \cdot e_{\mathrm{fP}}$ directly as discussed below.

Previous models of sea foam emissivity (Droppleman, 1970; Rozenkranz and Staelin, 1972) and new studies of foam dielectric and radiative properties (Anguelova, 2008; Anguelova and Gaiser, 2012, 2013) use high void fraction values, usually $f_{\mathrm{a}}>90 \%$. Such a high void fraction provides the high, black-body-like emissivity for foam-covered surfaces that has been observed in experiments (Rose et al., 2002; Raizer and Sharkov, 1982). However, even for high winds, $W$ is no more than 6-10\% (Callaghan et al., 2008). Therefore, when the high foam emissivity, $e_{\mathrm{f}}$, is weighted with a low value for $W$ to obtain the foam emissivity contribution with the product $W \cdot e_{\mathrm{f}}$ and brightness temperature, $T_{\mathrm{BfP}}$, due to foam in open ocean (Eq. 7), the net result is a relatively small contribution from foam (Anguelova, 2008, Fig. 12).
The most rigorous approach to evaluate $T_{\mathrm{BfP}}$ is to use Eq. (7), i.e., obtain foam emissivity, $e_{\mathrm{f}}$, from the void fraction, $f_{\mathrm{a}}$, and then weight it with the whitecap fraction, $W$. However, due to the lack of detailed information about the vertical distribution of void fraction, a simplified approach is used in H12. Because the penetration depth of $10.7 \mathrm{GHz}$ frequency is small compared to the thickness of a whitecap, the estimate of ocean surface emissivity can be reduced to a quasi-2-D (horizontal) problem. These considerations lead to an assumption that over a large footprint (i.e., many whitecaps) the average near-surface void fraction can be approximated with the whitecap fraction, i.e., $f_{\mathrm{a}}=W$. This simplification is unlikely to introduce significant errors to the foam emissivity estimate; however, strictly speaking it remains to be subject to further validations.

As shown in Eq. (8), another parameter contributing to the brightness temperature variation is the azimuth angle, $\phi$, i.e., the angle between the viewing direction and wind vector projections onto the plane of the ocean surface. At zenith angle $\theta=45^{\circ}$ and wind speed $U_{10}=10 \mathrm{~m} \mathrm{~s}^{-1}$, the azimuthal variation of the brightness temperature is about 1 to $2 \mathrm{~K}$ for $\mathrm{L}$ and K bands (e.g., Yueh et al., 1995, 2010). In the SPM/SSA model, the emissivity change can be expressed in azimuthal harmonic terms (Yueh et al., 1994b). To the second-order small-slope approximation, only the even terms up to the second harmonics can be resolved (Johnson and Zhang, 1999); that is,

$\delta e_{\mathrm{BP}}=\delta e_{\mathrm{BP}}^{(0)}+\delta e_{\mathrm{BP}}^{(2)} \cos (2 \varphi)$,

where harmonics $\delta e_{\mathrm{BP}}^{(2 n)}$ are determined using the dimensionless surface roughness spectrum. Equation (A2) is a relatively coarse representation of the directional distribution function. Note that model calculations presented in this paper do not take the azimuthal angle effect into consideration and, therefore, are considered integrated over this parameter. 
Acknowledgements. This work was sponsored by the Office of Naval Research (ONR), NRL Program element 61153N WUs nos. 4500 and 4278 . We greatly appreciate the funding support for our use of FLIP by Robert Schnoor via the Naval Research Facilities Program at ONR, and by Joan Gardner and Edward Franchi via the NRL Platform Support Program. Captain William Gaines, FLIP program manager at Marine Physics Laboratory (MPL) at Scripps Institution of Oceanography, was indispensable in organizing the field campaign. We appreciate Tom Golfinos, officer in charge for FLIP, and crew members Johnny, Dave, Frank, and Jerry for their hard work, endurance, and camaraderie. We would also like to thank George Trekas and his colleagues at the MPL Machine Shop for their expertise and skills in devising the instrument deployment on the FLIP booms. We tank two anonymous reviewers for their perusal of the manuscript, constrictive critique, and insightful suggestions.

Edited by: T. J. Dunkerton

\section{References}

Andreae, M.: Climatic effects of changing atmospheric aerosol levels, in: World Survey of Climatology, vol. 16, Future Climates of the World, edited by: Henderson-Sellers, A., 347-398, Elsevier, New York, 1995.

Andreas, E., Edson, J., Monahan, E., Rouault, M., and Smith, S.: The spray contribution to the net evaporation from the sea: A review of recent progress, Bound. Lay. Meteorol., 72, 3-52, 1995.

Andreas, E. L.: A review of the sea spray generation function for the open ocean, in: Atmosphere-Ocean Interactions, edited by: Perrie, W., 1. WIT Press, Southampton, UK, 1-46, 2002.

Anguelova, M. D.: Whitecaps, sea-salt aerosols, and climate, Ph.D. Dissertation, University of Delaware, 2002.

Anguelova, M. D.: Complex dielectric constant of sea foam at microwave frequencies, J. Geophys. Res., 113, C08001, doi:10.1029/2007JC004212, 2008.

Anguelova, M. D. and Gaiser, P. W.: Dielectric and radiative properties of sea foam at microwave frequencies: Conceptual understanding of foam emissivity, Remote Sensing, 4, 1162-1189, 2012.

Anguelova, M. D. and Gaiser, P. W.: Microwave emissivity of sea foam layers with vertically inhomogeneous dielectric properties, Remote Sens. Environ., 139, 81-96, 2013.

Anguelova, M. D. and Webster, F.: Whitecap coverage from satellite measurements: A first step toward modeling the variability of oceanic whitecaps, J. Geophys. Res., 111, C03017, doi:10.1029/2005JC003158, 2006.

Bettenhausen, M., Smith, C., Bevilacqua, R., Wang, N., Gaiser, P., and Cox, S.: A nonlinear optimization algorithm for WindSat wind vector retrievals, IEEE T. Geosci. Remote Sens., 44, 597610, doi:10.1109/TGRS.2005.862504, 2006.

Blanchard, D.: The production, distribution and bacterial enrichment of the sea-salt aerosol, in: Air-Sea Exchange of Gases and Particles, edited by: Liss, P. and Slinn, G., 407-454, Springer, New York, 1983.

Bobak, J. P., Dowgiallo, D. J., McGlothlin, N. R., and St. Germain, K. M.: APMIR: Airborne Polarimetric Microwave Imaging Radiometer, Proc. IGARSS, Sydney, Australia, 505-507, 2001.
Bobak, J. P., Asher, W. E., Dowgiallo, D. J., and Anguelova, M. D.: Aerial radiometric and video measurements of whitecap coverage, IEEE T. Geosci Remote Sens., 49, 2183-2193, 2011.

Caffrey, P. F., Hoppel, W. A., and Shi, J. J.: A one-dimensional sectional aerosol model integrated with mesoscale meteorological data to study marine boundary layer aerosol dynamics, J. Geophys. Res, 111, D24201, doi:10.1029/2006JD007237, 2006.

Callaghan, A., de Leeuw, G., Cohen, L., and O'Dowd, C. D.: Relationship of oceanic whitecap coverage to wind speed and wind history, Geophys. Res. Lett., 35, L23609, doi:10.1029/2008GL036165, 2008.

Camps, A., Font, J., Vall-llossera, M., Gabarro, C., Corbella, I., Duffo, N., Torres, F., Blanch, S., Aguasca, A., Villarino, R., Enrique, L., Miranda, J. J., Arenas, J. J., Julia, A., Etcheto, J., Caselles, V., Weill, A., Boutin, J., Contardo, S., Niclos, R., Rivas, R., Reising, S. C., Wursteisen, P., Berger, M., and Martin-Neira, M.: The WISE 2000 and 2001 field experiments in support of the SMOS Mission: Sea surface L-band brightness temperature observations and their application to sea surface salinity retrieval, IEEE T. Geosci. Remote Sens., 42, 804-823, 2004.

Chelton, D. B.: Seasonal variability of alongshore geostrophic velocity off Central California, J. Geophys. Res.-Oceans, 89, 3473 3486, 1984.

Cox, C. S.: Measurements of slopes of high-frequency wind waves, J. Mar. Res., 16, 199-225, 1958.

de Leeuw, G., Neele, F. P., Hill, M., Smith, M. H., and Vignati, E.: Sea spray aerosol production by waves breaking in the surf zone, J. Geophys. Res., 105, 29397-29409, 2000.

de Leeuw, G., Andreas, E. L., Anguelova, M. D., Fairall, C. W., Lewis, E. R., O'Dowd, C., Schulz, M., and Schwartz, S. E.: Production flux of sea spray aerosol, Rev. Geophys., 49, RG2001, doi:10.1029/2010RG000349, 2011.

Droppleman, J.: Apparent microwave emissivity of sea foam, J. Geophys. Res., 75, 696-698, 1970.

Fairall, C. W., Banner, M. L., Peirson, W. L., Asher, W., and Morison, R. P.: Investigation of the physical scaling of sea spray spume droplet production, J. Geophys. Res., 114, C10001, doi:10.1029/2008JC004918, 2009.

Frick, G. M. and Hoppel, W. A.: Airship measurements of ship's exhaust plumes and their effect on marine boundary layer clouds, J. Atmos. Sci., 57, 2625-2648, 2000.

Gathman, S. G., van Eijk, A. M. J., and Cohen, L. H.: Characterizing large aerosols in the lowest level of the marine atmosphere, Proc. SPIE 3433, Propagation and Imaging through the Atmosphere II, 41-52, 1998.

Gerber, H. E.: Relative-humidity parameterization of the Navy aerosol model (NAM), NRL Report 8956, Naval Research Laboratory, Washington, D.C., 1985.

Hollinger, J. P.: Passive microwave measurements of sea surface roughness, IEEE T. Geosci. Elect, 9, 165-169, 1971.

Hoppel, W. A., Frick, G. M., Fitzgerald, J. W., and Larson, R. E.: Marine boundary layer measurements of new particle formation and the effects nonprecipitating clouds have on aerosol size distribution, J. Geophys. Res., 99, 14443-14459, 1994.

Hoppel, W. A., Frick, G. M., and Fitzgerald, J. W.: Surface source function for sea-salt aerosol and aerosol dry deposition to the ocean surface, J. Geophys. Res., 107, AAC 7-1-AAC 7-17, 2002. 
Hwang, P. A.: Foam and roughness effects on passive microwave remote sensing of the ocean, IEEE T. Geosci. Remote, 50, 29782985, 2012.

Johnson, J. T.: An efficient two-scale model for the computation of thermal emission and atmospheric reflection from the sea surface, IEEE T. Geosci. Remote Sens., 44, 560-568, 2006.

Johnson, J. T. and Zhang, M.: Theoretical study of the small slope approximation for ocean polarimetric thermal emission, IEEE T. Geosci. Remote Sens., 37, 2305-2316, 1999.

Kara, A., Wallcraft, A., and Bourassa, M.: Air-sea stability effects on the $10 \mathrm{~m}$ winds over the global ocean: Evaluations of air-sea flux algorithms, J. Geophys. Res., 113, C04009, doi:10.1029/2007JC004324, 2008.

Koblinsky, C. J., Hildebrand, P., Le Vine, D., Pellerano, F., Chao, Y., Wilson, W., Yueh, S., and Lagerloef, G.: Sea surface salinity from space: Science goals and measurement approach, Radio Sci., 38, 8064, doi:10.1029/2001RS002584, 2003

Lafon, C., Piazzola, J., Forget, P., le Calve, O., and Despiau, S.: Analysis of the variations of the whitecap fraction as measured in a coastal zone, Bound.-Lay. Meteorol., 111, 339-360, 2004.

Large, W. G. and Pond, S.: Open Ocean Momentum Flux Measurements in Moderate to Strong Winds, J. Phys. Oceanogr., 11, 324-336, doi:10.1175/15200485(1981)011<0324:OOMFMI>2.0.CO;2, 1981.

Lewis, E. R. and Schwartz, S. E.: Sea salt aerosol production: mechanisms, methods, measurements, and models - a critical review, Geophys. Monogr. Ser., 152, 413 pp., AGU, Washington, DC, 2004.

Longuet-Higgins, M. S.: The generation of capillary waves by steep gravity waves, J. Fluid Mech., 16, 138-159, 1963.

Longuet-Higgins, M. S.: Capillary rollers and bores, J. Fluid Mech., 240, 659-679, 1992.

Lyzenga, D. R.: Comparison of WindSat brightness temperature with two-scale model prediction, IEEE T. Geosci. Remote Sens., 44, 549-559, 2006.

Meissner, T. and Wentz, F. J.: The complex dielectric constant of pure and sea water from microwave satellite observations, IEEE T Geosci. Remote Sens., 42, 1836-1849, 2004.

Melville, W. K.: The role of surface-wave breaking in air-sea interaction, Annu. Rev. Fluid Mech., 28, 279-321, 1996.

Monahan, E. C. and Lu, M. Z.: Acoustically relevant bubble assemblages and their dependence on meteorological parameters, IEEE J. Ocean. Eng., 15, 340-349, 1990.

Monahan, E. C. and O’Muircheartaigh, I. G.: Optimal power-law description of oceanic whitecap coverage dependence on wind speed, J. Phys. Oceanogr., 10, 2094-2099, 1980.

Monahan, E. C. and O'Muircheartaigh, I. G.: Whitecaps and the passive remote sensing of the ocean surface, Int. J. Remote Sens., 7, 627-642, 1986.

Monahan, E. C., Davidson, K. L., and Spiel, D. E.: Whitecap aerosol productivity deduced from simulation tank measurements, J. Geophys. Res., 87, 8898-8904, 1982.

Monahan, E. C., Fairall, C. W., Davidson, K. L., and Bovle, P. J.: Observed inter relations between $10 \mathrm{~m}$ winds, ocean whitecaps and marine aerosols, Q. J. Roy. Meteor. Soc., 109, 379-392, 1983.

Monahan, E. C., Spiel, D. E., and Davidson, K. L.: A model of marine aerosol generation via whitecaps and wave disruption, in: Oceanic whitecaps and their role in air sea exchange processes, edited by: Monahan, E. C. and MacNiocaill, G., 167-174, D. Reidel, Dordrecht, Netherlands, 1986.

Monin, A. C. and Obukhov, A. M.: Basic laws of turbulent mixing in the ground layer of the atmosphere, Trans. Geophys. Inst. Akad. Nauk, 151, 163-187, 1954.

Norris, S. J., Brooks, I. M., and Salisbury, D. J.: A wave roughness Reynolds number parameterization of the sea spray source flux, Geophys. Res. Lett., 40, 4415-4419, 2013.

Ovadnevaite, J., Manders, A., de Leeuw, G., Ceburnis, D., Monahan, C., Partanen, A.-I., Korhonen, H., and O’Dowd, C. D.: A sea spray aerosol flux parameterization encapsulating wave state, Atmos. Chem. Phys., 14, 1837-1852, doi:10.5194/acp-14-18372014, 2014.

Pandey, P. C. and Kakar, R. K.: An empirical microwave emissivity model for a foam-covered sea, IEEE J. Ocean. Eng., 7, 135-140, 1982.

Petelski, T.: Marine aerosol fluxes over open sea calculated from vertical concentration gradients, Aerosol Sci., 34, 359-371, 2003.

Petelski, T. and Piskozub, J.: Vertical coarse aerosol fluxes in the atmospheric surface layer over the north polar waters of the Atlantic, J. Geophys. Res., 111, C06039, doi:10.1029/2005JC003295, 2006.

Quinn, P. K., Coffman, D. J., Kapustin, V. N., Bates, T. S., and Covert, D. S.: Aerosol optical properties in the marine boundary layer during the First Aerosol Characterization Experiment (ACE-1) and the underlying chemical and physical aerosol properties, J. Geophys. Res., 103, 16547-16563, 1998.

Raizer, V. Ya and Sharkov, E. A.: Electrodynamic description of densely packed dispersed systems, Izvestiya Radiophys and Quantum Electronics, 24, 553-560, 1982.

Reid, J. S., Brooks, B., Crahan, K. K., Hegg, D. A., Eck, T. F., O'Neill, N., de Leeuw, G., Reid, E. A., and Anderson, K. D.: Reconciliation of coarse mode sea-salt aerosol particle size measurements and parameterizations at a subtropical ocean receptor site, J. Geophys. Res., 111, D02202, doi:10.1029/2005JD006200, 2006.

Reul, N. and Chapron, B.: SMOS-Salinity Data Processing Study: Improvements in emissivity models, IFREMER (Institut français de recherche pour l'exploitation de la mer) Tech. Rep. WP 1100, 130 pp., 2001.

Rose, L. A., Asher, W. E., Reising, S. C., Gaiser, P. W., St Germain, K. M., and Dowgiallo, D. J.: Radiometric measurements of the microwave emissivity of foam, IEEE T. Geosci. Remote Sens., 40, 2619-2625, 2002.

Rosenkranz, P. W. and Staelin, D. H.: Microwave emissivity of ocean foam and its effect on nadiral radiometric measurements, J. Geophys. Res., 77, 6528-6538, 1972.

Salisbury, D. J., Anguelova, M. D., and Brooks, I. M.: On the variability of whitecap fraction using satellite-based observations, J. Geophys. Res.-Oceans, 118, 6201-6222, 2013.

Shettle, E. P. and Fenn, R. W.: Models for the aerosols of the lower atmosphere and the effects of humidity variations on their optical properties, No. AFGL-TR-79-0214, Air Force Geophysics Lab Hanscom AFB MA, 1979.

Slinn, S. A. and Slinn, W. G. N.: Predictions of particle deposition on natural waters, Atmos. Environ., 14, 1013-1016, 1980. 
Smith, M. H., Park, P. M., and Consterdine, I. E.: Marine aerosol concentrations and estimated fluxes over the sea, Q. J. Roy. Meteor. Soc., 119, 809-824, 1993.

Stogryn, A.: The emissivity of sea foam at microwave frequencies, J. Geophys Res, 77, 1658-1666, 1972.

Swift, C. T.: Microwave radiometer measurements of the Cape Cod Canal, Radio Sci., 9, 641-653, 1974.

Textor, C., Schulz, M., Guibert, S., Kinne, S., Balkanski, Y., Bauer, S., Berntsen, T., Berglen, T., Boucher, O., Chin, M., Dentener, F., Diehl, T., Easter, R., Feichter, H., Fillmore, D., Ghan, S., Ginoux, P., Gong, S., Grini, A., Hendricks, J., Horowitz, L., Huang, P., Isaksen, I., Iversen, I., Kloster, S., Koch, D., Kirkevåg, A., Kristjansson, J. E., Krol, M., Lauer, A., Lamarque, J. F., Liu, X., Montanaro, V., Myhre, G., Penner, J., Pitari, G., Reddy, S., Seland, $\varnothing .$, Stier, P., Takemura, T., and Tie, X.: Analysis and quantification of the diversities of aerosol life cycles within AeroCom, Atmos. Chem. Phys., 6, 1777-1813, doi:10.5194/acp-6-1777-2006, 2006.

Ulaby, F., Moore, R., and Fung, A.: Microwave remote sensing: active and passive, Microwave Remote Sensing Fundamentals and Radiometry, vol. 1, Addison Wesley, 1981.

Wentz, F. J.: A two-scale scattering model for foam-free sea microwave brightness temperatures, J. Geophys. Res., 80, 34413446, 1975.

Wentz, F. J.: A well-calibrated ocean algorithm for special sensor microwave/imager, J. Geophys. Res.-Oceans, 102, 8703-8718, 1997.
Woolf, D. K.: Bubbles and the air-sea transfer velocity of gases, Atmos. Ocean, 31, 517-540, doi:10.1080/07055900.1993.9649484, 1993.

Wyllie, J. G.: Geostrophic flow of the California current at the surface and at $200 \mathrm{~m}$, Atlas, vol. 4, California Cooperative Oceanic Fisheries Investigations, La Jolla, Calif., 1966.

Yueh, S. H.: Modeling of wind direction signals in polarimetric sea surface brightness temperatures, IEEE T. Geosci. Remote Sens., 35, 1400-1418, 1997.

Yueh, S. H., Kwok, R., Li, F. K., Nghiem, S. V., Wilson, W. J., and Kong, J. A.: Polarimetric passive remote sensing of ocean wind vectors, Radio Sci., 29, 799-814, 1994a.

Yueh, S. H., Kwok, R., and Nghiem, S. V.: Polarimetric scattering and emission properties of targets with reflection symmetry, Radio Sci., 29, 1409-1420, 1994b.

Yueh, S. H., Wilson, W. J., Li, F. K., Nghiem, S. V., and Ricketts, W. B.: Polarimetric measurements of sea surface brightness temperatures using an aircraft K-band radiometer, IEEE T. Geosci. Remote Sens., 33, 85-92, 1995.

Yueh, S. H., Dinardo, S. J., Fore, A. G., and Li, F. K.: Passive and active L-band microwave observations and modeling of ocean surface winds, IEEE T. Geosci. Remote Sens., 48, 3087-3100, 2010.

Zhao, D. and Toba, Y.: Dependence of whitecap coverage on wind and wind-wave properties, J. Oceanogr., 57, 603-616, 2001. 